\title{
Towards the discovery of novel genetic component involved in stress resistance in Arabidopsis thaliana
}

\author{
Michal Juraniec ${ }^{1 *}$, Hélène Lequeux ${ }^{1,2 *}$, Christian Hermans ${ }^{1}$, Glenda Willems ${ }^{3,4}$, Magnus Nordborg ${ }^{3}$, \\ Korbinian Schneeberger ${ }^{4}$, Pietrino Salis ${ }^{1}$, Maud Vromant ${ }^{1}$, Stanley Lutts ${ }^{2}$ and Nathalie Verbruggen ${ }^{1}$ \\ ${ }^{1}$ Laboratory of Plant Physiology and Molecular Genetics, Université Libre de Bruxelles, 1050, Brussels, Belgium; ${ }^{2}$ Groupe de Recherche en Physiologie Végétale, Earth and Life Institute, \\ Université catholique de Louvain, 5 bte13, Croix du Sud, 1348, Louvain-La-Neuve, Belgium; ${ }^{3}$ Gregor Mendel Institute of Molecular Plant Biology, Austrian Academy of Sciences, \\ Dr. Bohr-Gasse 3, 1030, Vienna, Austria; ${ }^{4}$ Max Planck Institute for Plant Breeding Research, Carl-von-Linné-Weg 10, 50829, Cologne, Germany
}

Author for correspondence:

Nathalie Verbruggen

Tel: $+32(0) 26502128$

Email: nverbru@ulb.ac.be

Received: 8 August 2013

Accepted: 16 September 2013

New Phytologist (2014) 201: 810-824

doi: $10.1111 /$ nph.12554

Key words: Arabidopsis, copper-sensitive mutant, meristem, root growth, stress resistance.

\section{Summary}

- The exposure of plants to high concentrations of trace metallic elements such as copper involves a remodeling of the root system, characterized by a primary root growth inhibition and an increase in the lateral root density. These characteristics constitute easy and suitable markers for screening mutants altered in their response to copper excess.

- A forward genetic approach was undertaken in order to discover novel genetic factors involved in the response to copper excess. $\mathrm{A} \mathrm{Cu}^{2+}$-sensitive mutant named copper modified resistance1 ( $\mathrm{cmr} 1$ ) was isolated and a causative mutation in the $C M R 1$ gene was identified by using positional cloning and next-generation sequencing.

- CMR1 encodes a plant-specific protein of unknown function. The analysis of the $\mathrm{cmr} 1$ mutant indicates that the CMR1 protein is required for optimal growth under normal conditions and has an essential role in the stress response. Impairment of the CMR1 activity alters root growth through aberrant activity of the root meristem, and modifies potassium concentration and hormonal balance (ethylene production and auxin accumulation).

- Our data support a putative role for CMR1 in cell division regulation and meristem maintenance. Research on the role of CMR1 will contribute to the understanding of the plasticity of plants in response to changing environments.

\section{Introduction}

Copper $(\mathrm{Cu})$ is an essential metal for normal plant development but becomes rapidly toxic in excess. It is the cofactor of enzymes involved in many biochemical processes, including photosynthesis, respiration, detoxification of peroxide anions, ethylene perception and cell wall (CW) metabolism (Burkhead et al., 2009; Cohu \& Pilon, 2010). The average content of $\mathrm{Cu}$ in plant tissue ranges from 2 to $50 \mu \mathrm{g} \mathrm{g}^{-1} \mathrm{DW}$ (Epstein \& Bloom, 2005; Cohu \& Pilon, 2007). $\mathrm{Cu}$ is highly toxic as the redox cycling between $\mathrm{Cu}(\mathrm{I})$ and $\mathrm{Cu}(\mathrm{II})$ catalyses the production of hydroxyl radicals via Fenton's reaction (Drążkiewicz et al., 2004). Symptoms of toxicity usually appear when the $\mathrm{Cu}$ concentration exceeds $20 \mathrm{gg} \mathrm{g}^{-1} \mathrm{DW}$ in vegetative tissues (Marschner, 1995). Most of the genes up-regulated by $\mathrm{Cu}$ excess are not specific to $\mathrm{Cu}$, probably because they respond to the production of reactive oxygen species (ROS; Zhao et al., 2009). Different strategies have evolved in plants to regulate $\mathrm{Cu}$ homeostasis in response to available environmental $\mathrm{Cu}$, and several key players have already been identified, such as the family of $\mathrm{Cu}$ transporters (COPT), a Cu-transporting P-type ATPase (HMA5) or two $\mathrm{Cu}$

*These authors contributed equally to this work. chaperones, antioxidant protein1 (ATX1) and ATX1-like $\mathrm{Cu}$ chaperone (CCH; Puig \& Thiele, 2002; Sancenón et al., 2004; Hanikenne et al., 2005; Andrés-Colás et al., 2006, 2013; Shin et al., 2012).

Plants can adapt to an excess of trace metals in many ways; among others, they are capable of reorganizing their root system architecture (RSA) by inducing primary root (PR) growth inhibition and an increase in the lateral root (LR) density (Potters et al., 2007; Lequeux etal., 2010; Gruber et al., 2013; Verbruggen \& Hermans, 2013). Although the morphological changes are generic, they may not be induced through the same signaling pathway (Potters etal., 2007, 2009). Plant hormones, mainly auxin, cytokinin and ethylene, control RSA and remodel characteristics of the root, including PR and LR growth as well as root hair (RH) formation (Aloni etal., 2006; Nibau etal., 2008; Moubayidin et al., 2009; Potters et al., 2009).

The aim of this work is to better understand the mechanisms of $\mathrm{Cu}$ excess tolerance in plants by identifying novel genetic factors via forward genetics. A phenotypic screening, based on PR growth on high-Cu medium, was performed in Arabidopsis thaliana in order to find mutants with altered resistance to $\mathrm{Cu}$ excess. One $\mathrm{Cu}^{2+}$-sensitive mutant called copper modified resistancel ( $\mathrm{cmrl}$ ) was isolated and the CMR1 gene was identified. 
CMR1 is involved in meristem maintenance, which is necessary for optimal growth under control conditions and is required for survival under various environmental stresses.

\section{Materials and Methods}

\section{Plant material}

Three collections of Arabidopsis thaliana (L.) Col-0 seeds were screened: $\mathrm{M}_{2}$ ethyl methane sulfonate (EMS), fast neutron (FN)mutagenized (Lehle Seeds, Round Rock, TX, USA) and $\mathrm{T}_{4}$ T-DNA Weigel's lines (NASC, University of Nottingham, Loughborough, UK). The DR5::GUS reporter construct was provided by C. Périlleux (University of Liège, Belgium); $p C Y C B 1$; $1:: G U S$ and $p 35 S:: G U S$ by T. Beeckman (VIB, University of Ghent, Belgium); pme3 (Gabi-Kat line 00210, T-DNA in the first exon) by V. Lionetti (Sapienza University of Rome, Italy); SALK_070337 transformed with At3g14190 by R. Mercier (INRA Versailles-Grignon, France); and $p A C S 4:: G U S$ by Hong Kong University of Science and Technology (China). T-DNA lines for the At3g14190 locus (SALK_035661, SALK_070337, CS811152) were obtained from NASC and genotyped using appropriate primers (Supporting Information Table S11). The cmr1-1 was backcrossed three times to wild-type (WT) Col-0, while cmr1-2 (SALK_070337) was backcrossed once.

\section{In vitro growth conditions}

Seeds were surface-sterilized and plated on half-strength medium MS/2 (Murashige \& Skoog, 1962) agar media as described in Lequeux et al. (2010). The seedlings were grown on vertical plates under an $8: 16 \mathrm{~h}$, dark : light regime $\left(50 \mu \mathrm{mol} \mathrm{m}^{-2} \mathrm{~s}^{-1}\right)$ at $20^{\circ} \mathrm{C}$. For most experiments, seedlings were transferred $5 \mathrm{~d}$ after germination (DAG) onto MS/2 supplemented with or without selected stress agents. Root length measurements were performed using image analysis software RootSnap CI-690 (CID Bio-Science Inc., Camas, WA, USA).

\section{Mineral analysis}

Three-week-old in vitro-grown plants were harvested. Roots and shoots were washed with deionized water, dried at $60^{\circ} \mathrm{C}$ and crushed into fine powder. Elemental concentrations were determined as described in Gruber et al. (2013).

\section{Ethylene measurements}

Seedlings were grown as described in Lequeux etal. (2010). Ethylene production was quantified with the ETD300 photoacoustic ethylene detector (Sensor-Sense, Nijmegen, the Netherlands) as described in Cristescu et al. (2013).

\section{$\beta$-glucuronidase expression analysis}

$\beta$-Glucuronidase (GUS) expression analysis was performed as described in Lequeux et al. (2010).

\section{Confocal and scanning electron microscopy}

Root meristems of 1-wk-old seedlings were analysed using a Leica SP2 AOBS 405 microscope (Leica Microsystems, Mannheim, Germany). The material was incubated for $2 \mathrm{~min}$ in $10 \mu \mathrm{M}$ propidium iodide (PI) to stain cell walls (CWs) and was observed under an epifluorescence light with the appropriate filter set (excitation filter, BP $540-552 \mathrm{~nm}$; dichroic mirror, $565 \mathrm{~nm}$; barrier filter, $580-620 \mathrm{~nm}$ ). To quantify the size of meristem $\geq 30$ seedlings were collected from three growth experiments in two biological repeats. GFP fluorescence was analysed using a Zeiss LSM 710 microscope and detected with a 500-550 nm bandpass emission filter.

\section{DNA isolation, amplification and sequencing}

Frozen plant material was homogenized in extraction buffer (200 mM Tris-HCl, pH 7.5; $250 \mathrm{mM} \mathrm{NaCl;} 25 \mathrm{mM}$ EDTA, $\mathrm{pH} 8 ; 0.5 \%$ SDS). DNA was isolated using phenol extraction and precipitated with isopropanol. DNA used for genotyping or sequencing was amplified by PCR using Taq polymerase according to the manufacturer's protocol (Fermentas, Brussels, Belgium). DNA samples for sequencing were purified with DNA Clean \& Concentrator ${ }^{\mathrm{TM}}-5$ Kit (Zymo Research, Orange, CA, USA) according to the manufacturer's instructions and sequenced by MWG Biotech (Eurofins MWG Operon, Ebersberg, Germany).

\section{RNA extraction and cDNA synthesis}

Total RNA was extracted using the Aurum Total RNA Mini Kit (Bio-Rad, Nazareth Eke, Belgium) according to the manufacturer's instructions. cDNA was prepared using the RevertAid $\mathrm{H}$ Minus First Strand cDNA Synthesis Kit (Fermentas) according to the manufacturer's protocol.

\section{Genetic mapping}

Genetic mapping was performed as described in Hermans et al. (2010).

\section{Transcriptomic analysis}

Seeds of cmr1-1 and WT were germinated as described earlier. At 7 DAG, seedlings were transferred onto MS/2 supplemented with or without $25 \mu \mathrm{M} \mathrm{CuSO}_{4}$. Shoots and roots were harvested $24 \mathrm{~h}$ after the transfer and frozen in liquid nitrogen. Total RNA was extracted from $100 \mathrm{mg}$ of tissue powder using TRIzol according to the manufacturer's instructions (Rneasy, Qiagen, Venlo, the Netherlands). The RNA labelling and the microarray hybridization and scanning were performed at the Institute of Life Sciences at the Université catholique de Louvain-la-Neuve (Agilent microarray platform, http://www.uclouvain.be/en-276229.html). Genes whose expression was three times more induced or repressed (cutoff $=3$ ) in the mutant compared with the WT were used for further analysis. The MIPS 
functional catalogue database (http://mips.helmholtz-muenchen. de/proj/funcatDB/) was used to determine functional categories significantly regulated in $c m r l$ compared with WT.

\section{Illumina sequencing}

DNA was isolated from c. 300 mutant $\mathrm{F}_{2}$ plants using Genomic DNA Purification Kit (Fermentas) according to the manufacturer's instructions. The Illumina library was prepared using the Genomic Sample Prep Kit (Illumina, San Diego, CA, USA), according to the manufacturer's instructions. Insert size of the libraries correspond to $c .200 \mathrm{bp}$. Sequencing was performed by the sequencing core facilities at the Gregor Mendel Institute (Vienna, Austria). Paired-end reads of 75 bp length were generated on Illumina GAII. Reads were aligned to the Col-0 reference genome sequence using Burrows-Wheeler Aligner software (Li \& Durbin, 2009). Read alignments were visualized using Integrated Genomics Viewer (www.broadinstitute.org/software/igv/home).

\section{CMR1 coding sequence cloning}

At3g14190 coding sequence (CDS) was PCR-amplified using a $P f u$ polymerase according to the manufacturer's protocol (Fermentas). The blunt-end PCR product was cloned using the pENTR/D-TOPO cloning system. The LR reaction using a pK7WGF2 destination Gateway vector (Karimi et al., 2002) was performed according to the manufacturer's instructions (Invitrogen).

\section{Cellular localization of CMR1 in tobacco protoplast}

Seeds of tobacco (Nicotiana plumbaginifolia) were sown on MS medium containing $3 \%$ sucrose. The plants were grown under an $8: 16 \mathrm{~h}$, dark : light regime $\left(100 \mu \mathrm{mol} \mathrm{m}^{-2} \mathrm{~s}^{-1}\right)$ at $20^{\circ} \mathrm{C}$. Protoplasts were isolated from 2-month-old tobacco leaves and transformed as described in Hichri et al. (2010).

\section{Statistical analysis}

Results obtained with small sample size were analyzed using the nonparametric Wilcoxon-Mann-Whitney exact test for two independent groups (StatXact-9; Cytel Studio, Cambridge, MA, USA). For three or more independent groups, the nonparametric Kruskal-Wallis exact test was used, followed by a post hoc test. For relative means, statistical analyses were investigated using Student's $t$-test. For other results (obtained with large sample size), a parametric ANOVA with Tukey's multiple comparison test was performed using SAS 9.1 (SAS Institute Inc., Cary, NC, USA).

\section{Results}

Isolation of a copper-sensitive mutant and identification of its causative mutation

As, upon $\mathrm{Cu}^{2+}$ excess, root growth is significantly more affected than shoot growth (Lequeux et al., 2010) and PR length is easily quantifiable in vitro, a screening on vertical plates was performed in order to isolate mutants exhibiting root growth impairment in response to $\mathrm{Cu}^{2+}$ excess. Two different concentrations of copper sulphate were used: 25 and $50 \mu \mathrm{M}$. At $10 \mathrm{~d}$ after transfer (DAT), PR growth of WT plants was only slightly affected by $25 \mu \mathrm{M}$ $\mathrm{CuSO}_{4}$, which was chosen to screen for sensitive mutants. By contrast, PR growth of WT plants was severely inhibited in the presence of $50 \mu \mathrm{M} \mathrm{CuSO}_{4}$, which was used to identify tolerant mutants. About $42500 \mathrm{M}_{2}$ seedlings were screened on $25 \mu \mathrm{M}$ $\mathrm{CuSO}_{4}$ and 86 putative sensitive mutants were selected. However, only two mutants were confirmed in $\mathrm{M}_{3}$ (Table S1): one mutant was partially fertile and difficult to regenerate; the other one, derived from the FN-mutagenized population and named cmrl, which showed a relative PR growth reduction of $55 \%$ at 10 DAT (Fig. 1b,f), was studied further. About $16500 \mathrm{M}_{2}$ seedlings were screened on $50 \mu \mathrm{M} \mathrm{CuSO}_{4}$ and 12 putative tolerant mutants were selected, but none of them was confirmed in $\mathrm{M}_{3}$ (Table S1).

A map-based cloning was undertaken in order to identify the mutated locus responsible for the $c m r 1$ phenotype. An $\mathrm{F}_{2}$ population was generated from a cross between $c m r l$ in the Col- 0 background and WT Landsberg erecta (Ler-1). $\mathrm{F}_{1}$ seedlings grown in the presence of $\mathrm{CuSO}_{4}$ exhibited the WT phenotype and $25 \%$ of $\mathrm{F}_{2}$ were $\mathrm{Cu}$-sensitive, indicating that the $\mathrm{cmrl}$ mutation was recessive (data not shown). The DNA samples of $\mathrm{F}_{2} \mathrm{Cu}$-sensitive mutant individuals were analysed. The lowest recombination frequencies were calculated within the upper arm of the third chromosome. Subsequently, fine-mapping $\left(>1500 \mathrm{~F}_{2}\right.$ individuals tested) allowed the delimitation of a $184-\mathrm{kb}$ region of interest comprised between IN464 and IN482 markers (Fig. S1; Table S7) containing 53 genes (Table S2). Genes with a putative function in stress tolerance were sequenced in the $c m r l$ background, and corresponding T-DNA knockout mutants were phenotyped on high $\mathrm{Cu}$, but no candidate could be confirmed. Therefore, other approaches were followed to define the causative mutation. To verify the expression of candidate genes within the $184 \mathrm{~kb}$ mapped region, a microarray analysis of $c m r l$ was undertaken. At3g14310, which encodes PECTIN METHYLESTERASE 3, was strongly repressed in $c m r 1$ as compared with WT in control and high-Cu conditions (Table S3). However, the pme3 knockout mutant was not $\mathrm{Cu}^{2+}$-sensitive (Fig. S2a). Among the genes differentially expressed between $c m r 1$ and WT, no differences in sequences were found, except for At3g14190, which could not be PCR-amplified in $\mathrm{cmrl}$ (using primers at positions -487 and +314; Fig. S3), indicating the presence of a possible mutation at this locus. The At3g14190 mRNA levels were higher in $\mathrm{cmrl}$ than in WT in all tested conditions (Table S3), which was also confirmed by reverse transcription polymerase chain reaction (RT-PCR) (data not shown).

In parallel, a SHOREmap approach was followed. By deep sequencing of a pool of $F_{2}$ mutant individuals, the location of the mutation can be inferred based on the relative allele frequency observed at the single nucleotide polymorphism (SNP) markers between Col-0 and Ler-1 accessions (Schneeberger et al., 2009). However, since the mutant $c m r l$ line was obtained through FN mutagenesis, which mostly induces big insertions or deletions 


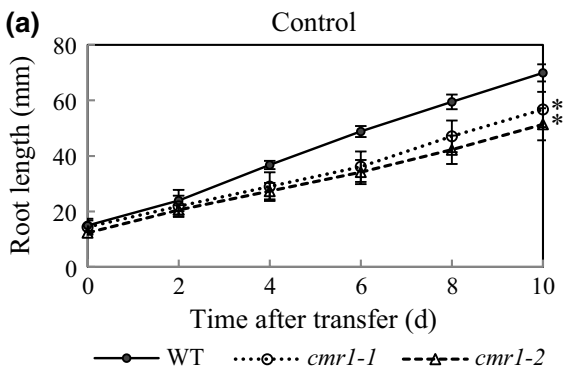

(c) Root growth inhibition upon copper addition
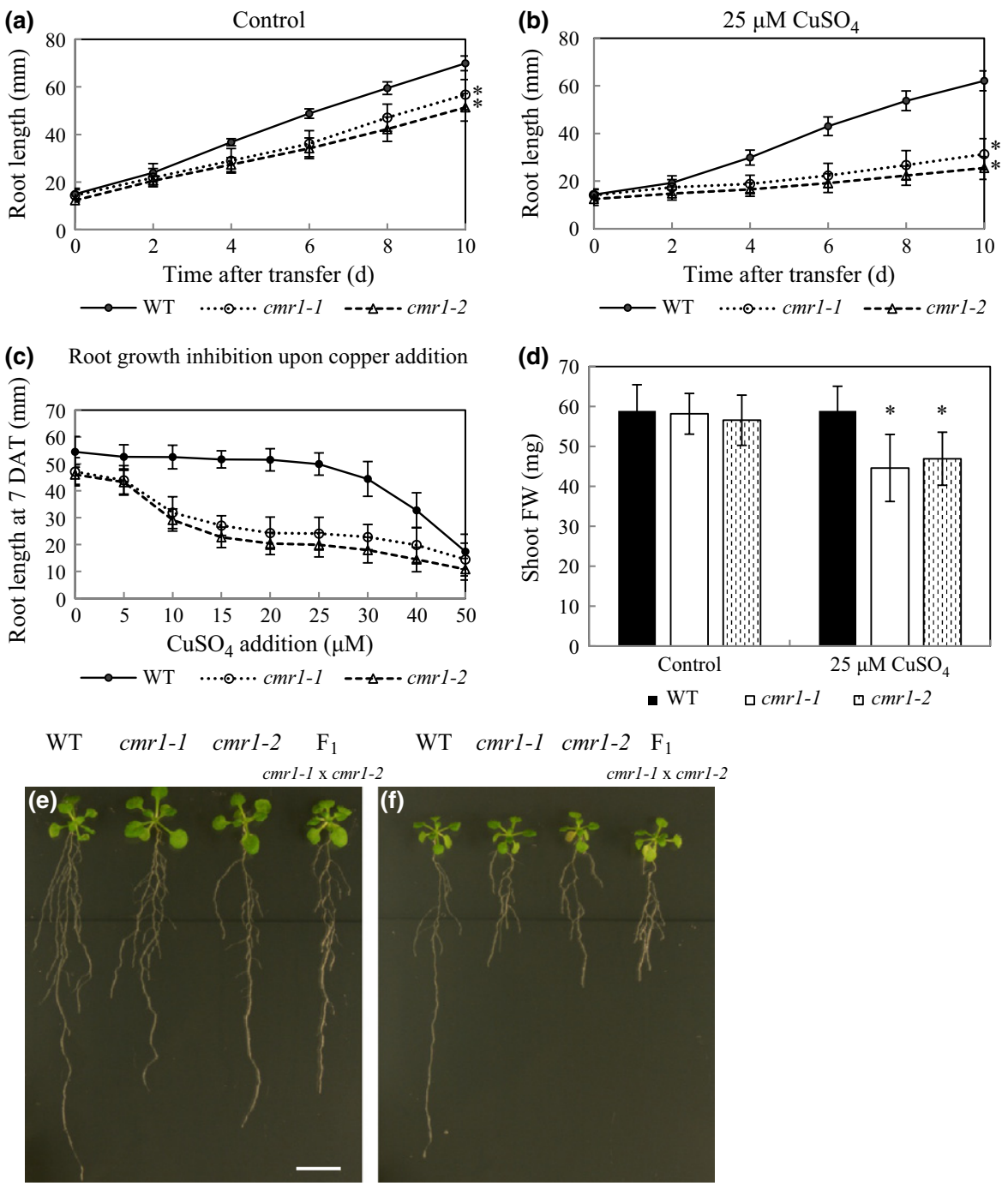

$\mathrm{MS} / 2$ cmrl-1 x cmrl-2

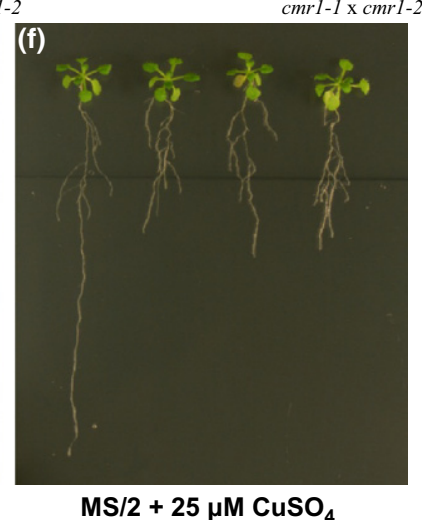

rather than point mutations (Li \& Zhang, 2002; Alonso \& Ecker, 2006; Belfield et al., 2012), SHOREmap was unsuccessful in identifying candidate SNPs at which the mutation could have taken place in the $184 \mathrm{~kb}$ interval. Consequently, after aligning paired-end reads using BWA (Li \& Durbin, 2009), coverage and read alignments were analysed in the $184 \mathrm{~kb}$ interval. Visual inspection of $c m r 1$ read coverage to the WT Col-0 reference genome revealed the presence of two low-coverage regions: one in the At3g14190 gene and the other in the At3g14310 gene (Fig. S4). Moreover, some read pairs, normally spaced c. $200 \mathrm{bp}$ apart, were broken. One end of these read pairs was mapped in the At3g14190 gene, while the other end of the read pairs was aligned to the At3g14310 gene. Those genes are spaced in the reference genome $65 \mathrm{~kb}$ apart (Fig. S5). Sequencing of DNA segments amplified using primers belonging to both genes (Fig. S6a-d) showed that a $65 \mathrm{~kb}$ inversion occurred between At3g14190 and At3g14310 loci (Fig. S6e). As a consequence, the promoter region and the first 160 nucleotides of the At3g14310 CDS were placed upstream the At3g14190 CDS but not in frame (Fig. S6f). Moreover, because of the reading frame shift, a stop codon appeared 165 bp downstream of the At3g14310 start codon, explaining why the expression of At3g14310 was strongly down-regulated in cmrl (Table S3). As a result, both genes are disrupted in $c m r l$.

To confirm the role of the At3g14190 gene in the cmrl stresssensitive phenotype, the response to $\mathrm{CuSO}_{4}$ excess was investigated using available T-DNA lines (Table S4). Three lines carrying the T-DNA in the At3g14190 CDS (SALK_035661, SALK_070337 and CS811152) exhibited a $\mathrm{Cu}^{2+}$-sensitive phenotype similar to that of $\mathrm{cmrl}$ (Fig. $2 \mathrm{a}$ ), confirming the involvement of the At3g14190 gene product in $\mathrm{CuSO}_{4}$ tolerance. A test for allelism was performed by crossing $c m r 1$ to the T-DNA lines. The $\mathrm{F}_{1}$ exhibited a similar $\mathrm{Cu}^{2+}$-sensitive phenotype to $\mathrm{cmrl}$ (Fig. 2a,b). The SALK_070337 was chosen for further work and was designated the cmr1-2 allele, while the original FN-induced mutant allele was named cmr1-1. Additionally, a functional complementation of $c m r 1-2$ with the genomic sequence of CMRI was performed to confirm that the loss of function of the At3g14190 gene was responsible for $\mathrm{Cu}$-modified resistance. Four independent homozygous transformants were selected and 
Fig. 2 Allelism test between Arabidopsis cmr1-1 and T-DNA mutants at the At3g14190 locus. (a) Pictures were taken $10 \mathrm{~d}$ after germination on MS/2 or the same medium supplemented with $25 \mu \mathrm{M} \mathrm{CuSO}_{4}$. (b) Quantification of root lengths in $\mathrm{Cmr1-1}$, cmr1-2 (SALK_070337) and their $\mathrm{F}_{1}$ progeny grown in control and high-Cu conditions for $7 \mathrm{~d}$ after transfer. Average values $(n \geq 30$ seedlings from three different growth experiments) $\pm S D$; asterisks denote significant differences from the wild-type (WT) within each treatment at $P \leq 0.05$. (c) Root length in the cmr1-2 knockout mutant and four independent lines transformed with the WT copy of the CMR1 gene in response to $\mathrm{Cu}$ excess in vitro. Seedlings were transferred $5 \mathrm{~d}$ after germination onto $\mathrm{MS} / 2$ medium supplemented with $25 \mu \mathrm{M} \mathrm{CuSO}_{4}$ for $1 \mathrm{wk}$. Average values ( $n \geq 30$ seedlings from three growth experiments) $\pm \mathrm{SD}$; asterisks denote a significant difference in the mutant as compared with the WT at $P \leq 0.05$. WT, black bar; cmr1-2 KO, dashed bar; cmr1-2 transformed lines with $C M R 1$ genomic sequence, grey bars.
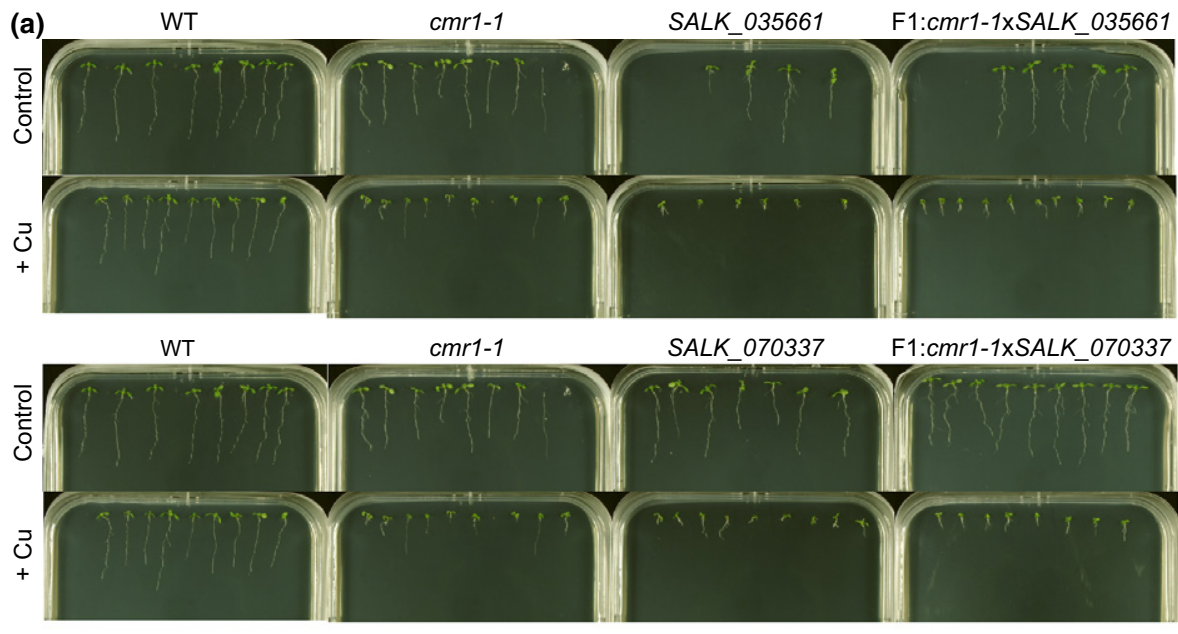

WT

cmr1-1

CS811152

F1:cmr1-1xCS811152

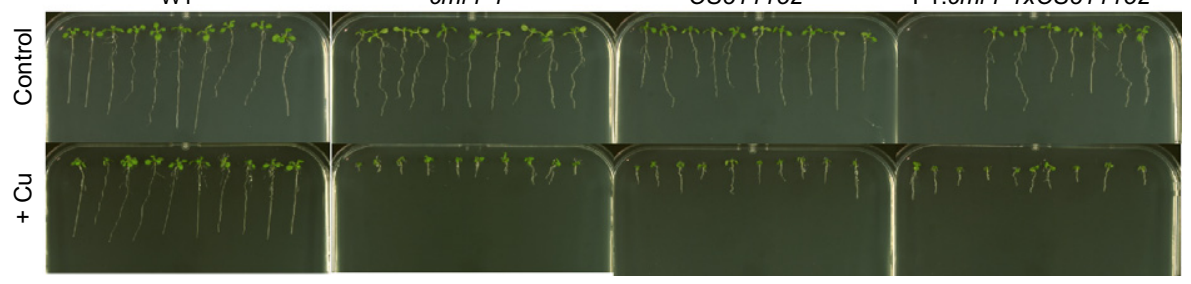

(b)

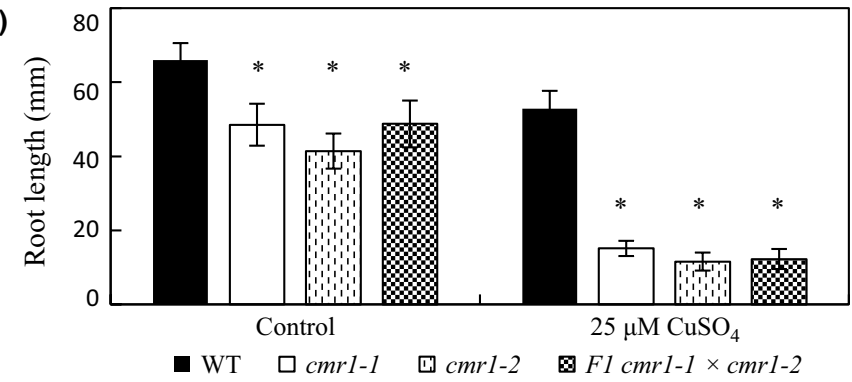

(c)

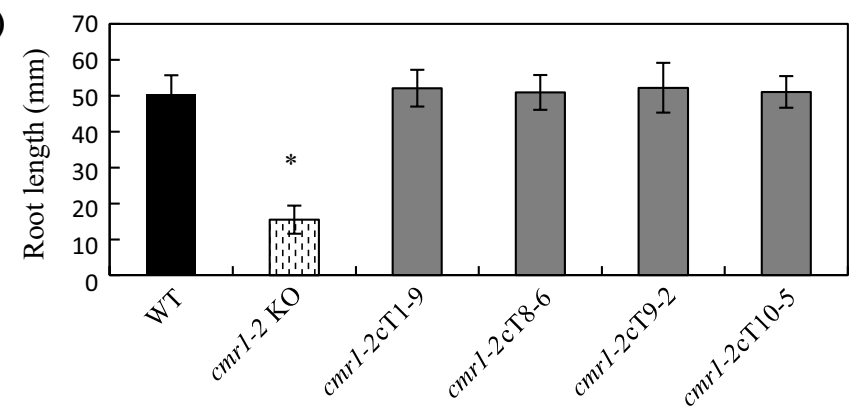

tested on $25 \mu \mathrm{M} \mathrm{CuSO}_{4}$. All lines exhibited restored root length, further supporting the idea that mutation at the At3g14190 locus was responsible for the $\mathrm{Cu}^{2+}$-sensitive phenotype in $\mathrm{cmrl}$ (Fig. 2c).

\section{In silico analysis of the At3g14190 gene}

The At3g14190 gene, which we called CMRI once the mutant was isolated, encodes a plant-specific protein of unknown function, predicted to be involved in cell proliferation and localized in the nucleus (www.arabidopsis.org). The corresponding deduced
CMR1 protein has a predicted molecular weight of $21.7 \mathrm{kDa}$ and a size of 193 amino acids. The sequence comprises a destruction box motif (D-box) RKALNDITN in the N-terminal region of the protein (http://bioinfo.weizmann.ac.il/ $\sim$ danag/d-box/main.html), which is a target for ubiquitin-dependent proteasome proteolysis (Vandepoele et al., 2002). Cyclebase.org indicates that the expression of the At3g14190 gene is modulated during the cell cycle with a peak at the early G1 phase (Gauthier et al., 2008). CMR1 shares $43 \%$ identity with the At5g12360 gene. Interestingly, a homolog of At3g14190 was identified in rice, sharing 33\% identity within the N-terminal sequence comprising the D-box, and the 
corresponding mutant rice salt sensitivel (rss I) was described (Ogawa et al., 2011). In addition, CMR1 shares significant identity with proteins from other plant species, such as Arabidopsis lyrata, Populus trichocarpa, Vitis vinifera and Glycine max, all with unknown functions. No CMR1-homologue was found in any other organisms than plants. According to Genevestigator.org, the organs with the highest CMR1 expression level are the ovule, the inflorescence shoot apex, the rosette shoot apex and axillary shoot, the silique replum, the root tip (RT) meristem and the shoot apical meristem.

\section{Subcellular localization of CMR1}

A nuclear localization of CMR1 was predicted using PSORT software (http://wolfpsort.org/). The presence of a nuclear localization signal in its sequence (PIHRKKS) was detected. We fused the CDS of the At3g14190 gene to the GFP sequence under the control of the $35 \mathrm{~S}$ promoter in the pK7WGF2 binary vector and checked its expression in tobacco protoplasts. The same but nonrecombined vector was used as a control. Fluorescence was localized in both the nucleus and the cytoplasm (Fig. 3).

\section{Growth of $\mathrm{cmr} 1$ in control and stress conditions}

The phenotypes of $c m r 1-1$ and $c m r 1-2$ were further characterized in control and on $\mathrm{Cu}$ excess conditions. In all tested conditions, the root growth of cmrl-1 and cmrl-2 was not significantly different. On control medium, both mutants displayed identical seed germination rates but exhibited significant $(P \leq 0.05)$

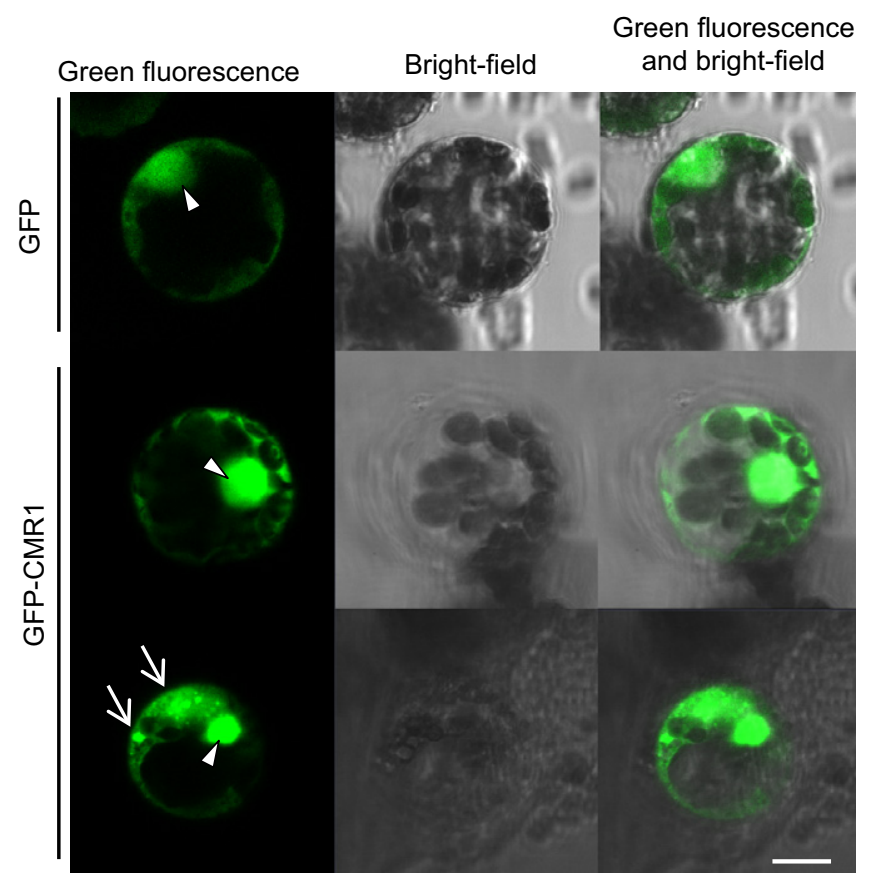

Fig. 3 Nuclear localization of the GFP_CMR1 fusion protein. Tobacco protoplasts were transformed with an empty vector pK7WGF2 as a control or with the same vector containing the GFP fused to the N-terminal of the CMR1 gene and placed under control of the $35 \mathrm{~S}$ promoter. Triangles indicate the nucleus, while arrows indicate inclusion bodies. Bar, $10 \mu \mathrm{m}$. reduction of root elongation rate by $-20 \%$ at 10 DAT compared with WT (Figs 1a,e, 2a,b). Growth on a $\mathrm{Cu}$ gradient was measured at 7 DAT. Both mutants showed $\pm 40 \%$ root length reduction after transfer onto $10 \mu \mathrm{M} \mathrm{CuSO}_{4}$ (Fig. 1c). Above $25 \mu \mathrm{M}$ $\mathrm{CuSO}_{4}$, the WT root growth sharply decreased. $\mathrm{Cu}$ sensitivity was also observable in shoots as their biomass was reduced by $\pm 20 \%$ in both mutants as compared with WT at 7 DAT onto $\mathrm{MS} / 2$ supplemented with $25 \mu \mathrm{M} \mathrm{CuSO}_{4}$ (Fig. 1d). No difference was measured in shoot biomass between WT and mutants at 7 DAT in control conditions. The stress-sensitive phenotype of cmr1-1 was also confirmed in older plants grown in hydroponic culture; however, the growth inhibition was weaker than the one observed in in vitro-grown seedlings (Fig. S7).

To verify the specificity of the $c m r 1$ phenotype, root growth in response to various abiotic stresses, especially trace metallic elements and osmoticum, was analysed (Fig. 4). Applied stresses were selected on the basis of their inhibitory effect on root growth in WT, to be comparable to $25 \mu \mathrm{M} \mathrm{CuSO}$. cmrl-2 was significantly $(P \leq 0.05)$ sensitive to the excess of $\mathrm{MnCl}_{2}$, $\mathrm{CoCl}_{2}, \mathrm{CdSO}_{4}$ and $\mathrm{ZnCl}_{2}$, as shown by a root length reduction of $8,53,56$ and $75 \%$, respectively, as compared with WT. cmr1-2 root growth was particularly sensitive to salt stress, with an inhibition of $90 \%$ on $50 \mathrm{mM} \mathrm{NaCl}$ (Fig. 4b). The cmrl-2 PR growth was also inhibited upon both $50 \mathrm{mM} \mathrm{KCl}$ and $10 \mathrm{mM} \mathrm{LiCl}$ treatment as compared with WT, as well as on $\mathrm{Na}_{2} \mathrm{SO}_{4}$ and $\mathrm{K}_{2} \mathrm{SO}_{4}$ excess and sorbitol, reaching 85, 92, 72, 82 and 54\%, respectively, of length reduction. A similar range of sensitivity was measured in cmr1-1 (data not shown). All these data indicate that both $\mathrm{cmrl}$ alleles are sensitive to various abiotic stresses and without any specificity to mono- or divalent ions. The root growth on $50 \mathrm{mM} \mathrm{NaCl}$ was also checked in the $\mathrm{F}_{1}$ derived from the cross between the two $\mathrm{cmrl}$ mutant alleles (Fig. S8a). The PR length measured 30\% of that in WT (Fig. $\mathrm{S} 8 \mathrm{~b}) . \mathrm{Ca}^{2+}$ ions are known to ameliorate $\mathrm{Na}^{+}$toxicity symptoms by decreasing $\mathrm{Na}^{+}$influx (Shabala et al., 2006). We checked whether the addition of $\mathrm{Ca}^{2+}$ had a beneficial impact on the $\mathrm{Na}^{+}$-sensitive phenotype of $\mathrm{cmrl}-1$. Although the addition of $10 \mathrm{mM} \mathrm{Ca}\left(\mathrm{NO}_{3}\right)_{2}$ slightly reduced the PR growth in cmrl-1 upon control conditions, it only partially restored the PR length during $\mathrm{NaCl}$ stress (data not shown).

\section{Mineral profile of $\mathrm{cmr} 1$}

To investigate the possible impact of the $c m r 1$ mutations on $\mathrm{Cu}$ and other essential element homeostasis, mineral analyses of 3 -wk-old seedlings grown on control, $25 \mu \mathrm{M} \mathrm{CuSO}_{4}$ - or $25 \mathrm{mM}$ $\mathrm{NaCl}$-supplemented media were assayed (Fig. 5; Tables S5,S6). No significant $(P \leq 0.05)$ differences in $\mathrm{Cu}$ concentration of root and shoot organs were observed between WT and mutant genotypes, regardless of the $\mathrm{Cu}$ or salt treatments. Interestingly, potassium $(\mathrm{K})$ content was significantly lower in both control and stress conditions (Fig. 5, Table S6). In control conditions, the $\mathrm{K}$ concentrations of root and shoot tissues were one-tenth less in $c m r 1-1$ and one-fifth less in $c m r 1-2$, respectively, compared with WT. Upon $\mathrm{Cu}$ exposure, cmr1-1 contained 44 and $26 \% \mathrm{~K}$ less in shoots and roots, respectively, than the WT 
(a)

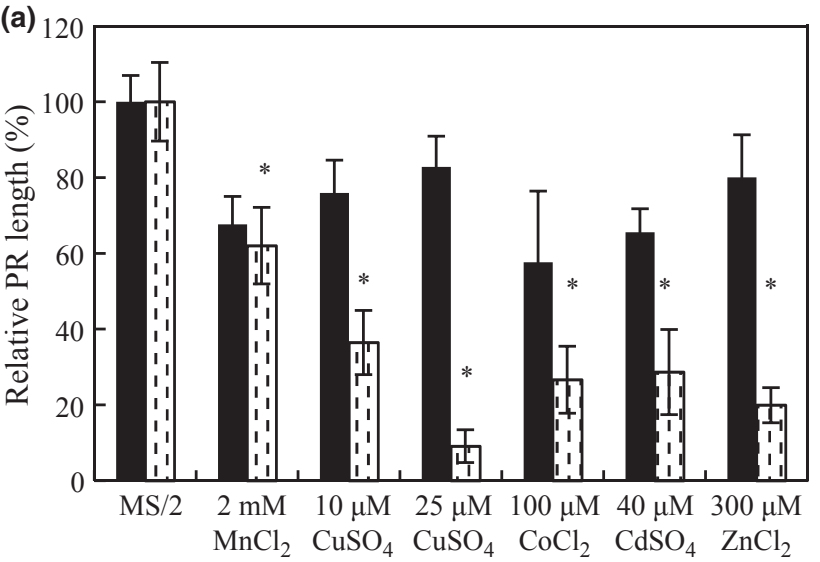

(b)

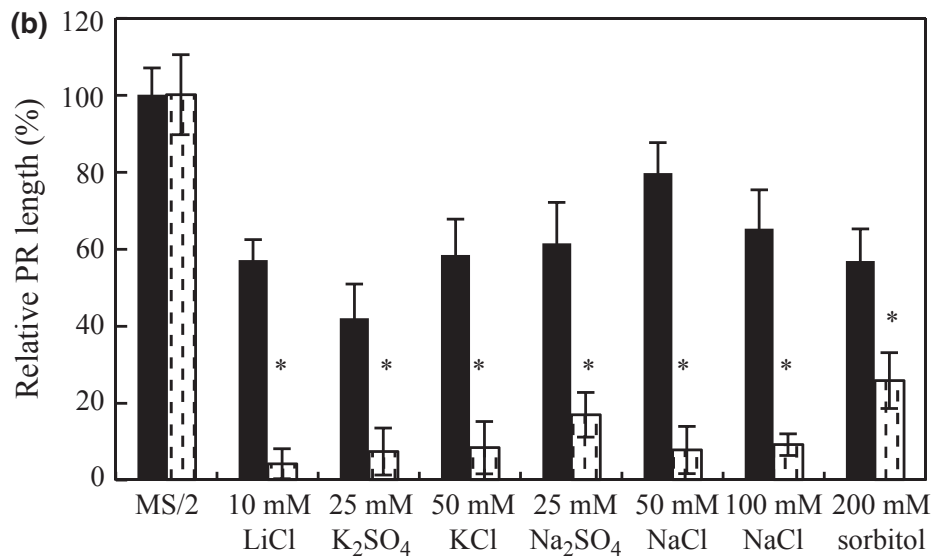

Fig. 4 Relative primary root (PR) growth of $\mathrm{cmr1}-2$ Arabidopsis plantlets in response to various external nutritional stimuli (a) and osmoticum (b) measured $10 \mathrm{~d}$ after transfer onto $\mathrm{MS} / 2$ medium $\left(0.1 \mu \mathrm{M} \mathrm{CuSO}_{4}\right)$ or on the same medium supplemented with an excess of different chemicals. Average values ( $n \geq 30$ seedlings from three independent experiments) \pm SD; asterisks denote significant differences between the cmr1-2 mutant and the wild-type (WT) within each treatment at $P \leq 0.05$ (WT, black bars; $c m r 1-2$, dashed bars).

(a)
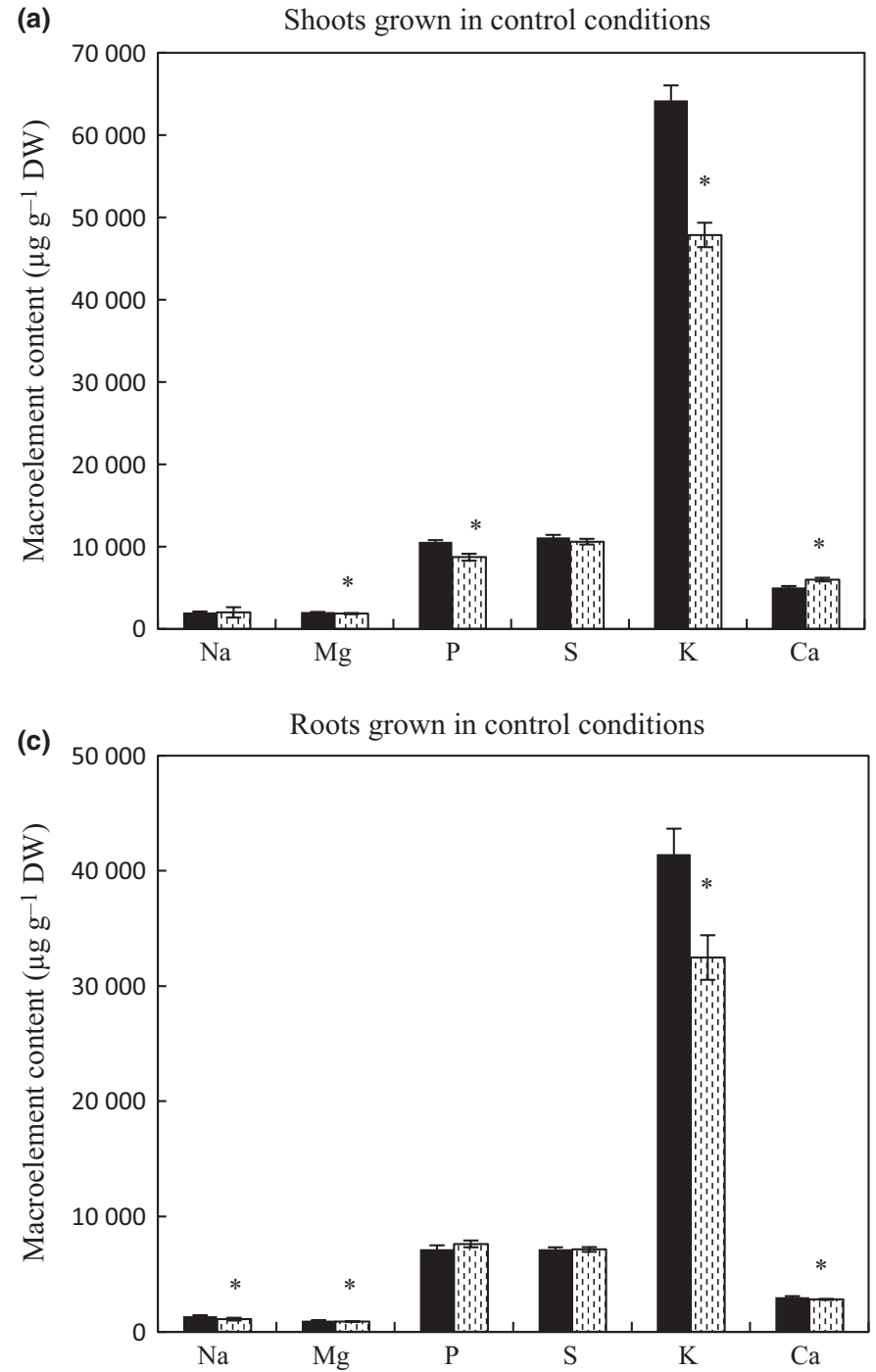

(b)

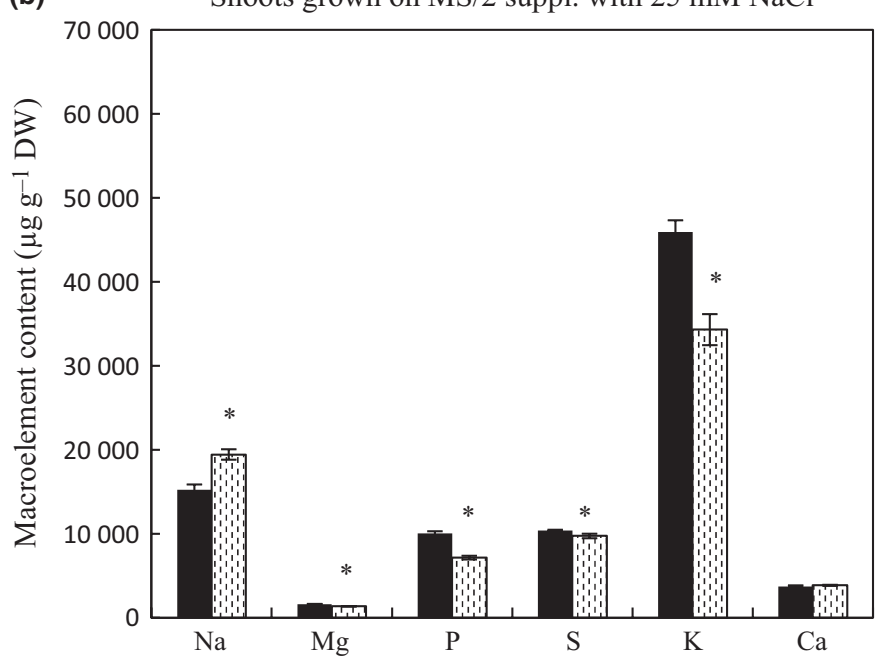

(d)

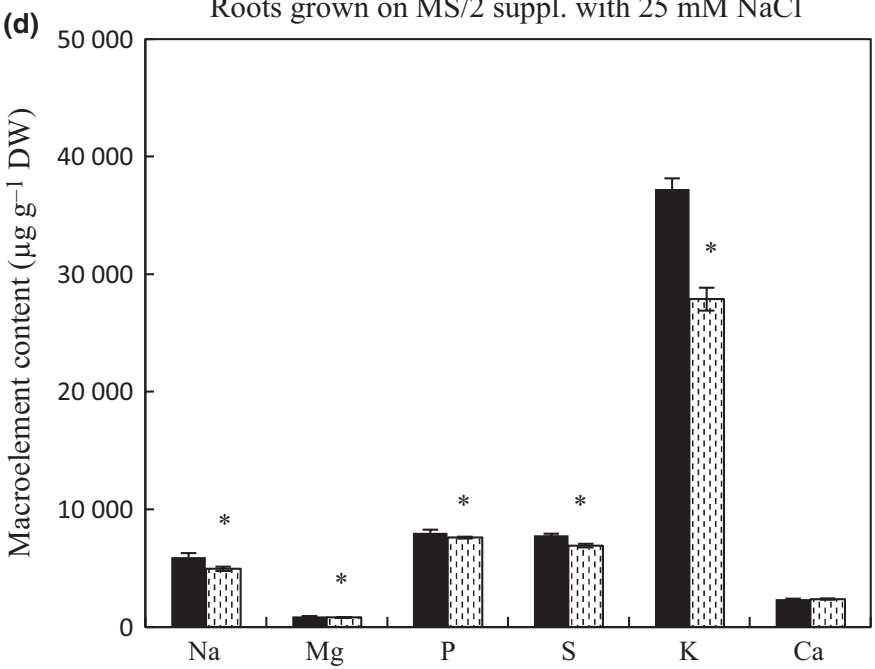

Fig. 5 Macronutrient and sodium content in in vitro-grown cmr1-2 Arabidopsis plants. Shoots and roots were harvested separately 3 wk after transfer onto $\mathrm{MS} / 2$ medium $(\mathrm{a}, \mathrm{c})$ or on the same medium supplemented with $25 \mathrm{mM} \mathrm{NaCl}(\mathrm{b}, \mathrm{d})$. Mineral concentrations are expressed in $\mu \mathrm{g} \mathrm{g} \mathrm{g}^{-1} \mathrm{DW}$. Values are means of five pools of $c$. 80 organs each $\pm \mathrm{SE}$. Asterisks indicate significant differences from the wild-type (WT) at $P \leq 0.05$ (WT, black bars; $\mathrm{cmr1}$-2, dashed bars). 
(Table S6). Upon $\mathrm{NaCl}$ exposure, $\mathrm{K}$ concentration in tissues was lower in cmr1-2 than in WT, with a difference of onefourth in both shoots and roots. Besides, cmr1-2 exhibited significantly higher $\mathrm{Zn}$ concentration in roots upon $\mathrm{NaCl}$ excess and higher Mo in both shoots and roots in control conditions and during salt stress (Table S5).

\section{The root tip phenotype of $\mathrm{cmr} 1$}

As a particular swelling of RT was systematically noticed in the cmr 1 mutants after transfer to $\mathrm{Cu}$ - or $\mathrm{NaCl}$-enriched media, a detailed observation of RT was conducted using light and confocal microscopy. In control conditions, except for the presence of longer RHs, cmrl RT showed no specific morphological changes (Fig. 6b). However, at $6 \mathrm{DAT}$ onto $25 \mu \mathrm{M} \mathrm{CuSO}_{4}$, cmr1 RTs were swollen and formation of numerous RHs was induced. In cmrl, the RH initiation region was closer to the root meristem and RHs were longer than those of WT. In contrast to WT, in which RH formation was inhibited upon salt stress (Fig. 6a), cmrl had abundant RHs close to the root apex (Fig. 6b). Furthermore, the root phenotype of $c m r l$ upon salt stress was much more pronounced than that upon $\mathrm{Cu}$ stress: RHs were longer and the swelling of RT was greater. To get a better insight into RT anatomy and its cellular organization, PI staining of CWs was performed in in vitro-grown seedlings of $\mathrm{cmrl}-2$ in control, $\mathrm{Cu}$ and saline conditions (Fig. 6c-g). In control conditions, the shape of cells, especially those in the cortical and epidermal layers, was less regular in cmr1-2 and cells were often slightly bigger than those in the WT (Fig. 6d). Growth upon $25 \mu \mathrm{M} \mathrm{CuSO}_{4}$ induced a reduction of meristem size in mutant roots; additionally, the cell shape and size were strongly altered. Cell layers within each tissue were irregular. This phenotype was even stronger upon $\mathrm{NaCl}$ stress conditions, where cells were highly irregular and the differentiation zone appeared just after the reduced meristem. Detailed examination of the meristem revealed perturbations during cell proliferation in $c m r 1-2$, and asymmetric divisions were detected in control conditions (Fig. 6f). When the mutant was exposed to salt stress, the functioning of the meristem was damaged and new CWs were inserted arbitrarily, causing a highly irregular cellular pattern (Fig. 6g). The size of root meristem can be examined by measuring the number of cortical cells in a file extending from the quiescent centre to the first elongated cell (Perilli \& Sabatini, 2010). A small but significant $(P \leq 0.05)$ decrease in the number of meristematic cortex cells of 7-d-old seedlings in control conditions was observed in cmrl-2 compared with WT (25 \pm 4 vs $29 \pm 3$ cells). Upon exposure to high $\mathrm{Cu}$ or salt, the RT was visibly reduced in the mutant (Fig. 6d). However, owing to the irregular cellular pattern, it was difficult to quantify the number of cells.

In order to check the effect of CMR1 loss of function on cell divisions, an introgression of $p C Y C B 1 ; 1:: G U S$ construct into the cmr1-1 background was generated. In WT cells, CYCB1;1 is expressed in late $S$ to mid-M phase cells (Colón-Carmona et al., 1999; Dohmann etal., 2008; Wu et al., 2010). In WT roots, independently of growth conditions, GUS expression under the activity of $C Y C B 1 ; 1$ promoter was weak and punctuate, reflecting the population of cells undergoing mitosis at the time of staining (Fig. 7). By contrast, in the $c m r 1-1$ root meristem, the pattern of staining was still patchy, but the number of blue-stained cells and staining itself increased considerably after $48 \mathrm{~h}$ of $\mathrm{Cu}^{2+}$ treatment.

\section{Hormonal imbalance in cmr1-1}

Root morphological characteristics of $\mathrm{cmrl}$ could be linked to ethylene, namely inhibition of root growth (Le et al., 2001; Swarup et al., 2007), RT swelling (Smalle \& Van Der Straeten, 1997) and induction of ectopic RHs (Tanimoto et al., 1995). Therefore, we monitored the gaseous hormone production of whole seedlings grown vertically on agar media (Fig. 8a-c). Ethylene production of $c m r 1-1$ was similar to that of WT under control conditions and twice as much after treatment with $25 \mu \mathrm{M}$ $\mathrm{CuSO}_{4}$. Under salt stress, no difference between $c m r 1-1$ and WT could be detected. To examine the production of the ethylene precursor, 1-aminocyclopropane-1-carboxylate (ACC), the ACC SYNTHETASE 4 pACS4::GUS construct was introgressed into the $c m r l$ background. In contrast to normal conditions, where weak GUS staining was visible in the root meristem, strong and patchy pattern staining was observed in $\mathrm{cmrl}$ at $2 \mathrm{DAT}$ onto $25 \mu \mathrm{M} \mathrm{CuSO}{ }_{4}$ (Fig. 8d). That observation further supports higher ethylene production. In both control and high- $\mathrm{Cu}$ conditions, weak staining was detected in the vascular regions of the differentiated zone in the mutant root, in contrast to WT. The impact of silver (an inhibitor of ethylene biosynthesis) on the root mutant phenotype was tested. The addition of $1 \mu \mathrm{M} \mathrm{Ag}_{2} \mathrm{SO}_{4}$ was not able to ameliorate the $c m r l$ root growth considerably (Fig. 8e) or to restore normal pACS4::GUS staining (data not shown) upon high-Cu exposure. A similar result was observed for another inhibitor, aminoethoxyvinylglycine (data not shown). As ethylene up-regulates root auxin biosynthesis in order to maximize its ability to inhibit root cell expansion (Swarup etal., 2007), the activity of GUS in cmrl crossed to the DR5::GUS reporter line was analysed to monitor auxin signals (Ulmasov et al., 1997). Compared with the WT background, RT in cmr1-1 exposed to 25 and $50 \mu \mathrm{M} \mathrm{CuSO}_{4}$ showed stronger GUS activity, reflecting an increased accumulation of IAA (Fig. 8f,g). In the control medium, the staining in $c m r l-1$ was similar to that in the WT.

\section{Discussion}

Plants have evolved different strategies to cope with high concentrations of $\mathrm{Cu}$. The goal of this work was to identify novel genetic components involved in $\mathrm{Cu}$ tolerance. $\mathrm{Up}$ to now, forward genetics have only allowed the identification of one $\mathrm{Cu}^{2+}$-sensitive mutant, cup1-1, on high-cadmium medium, of which the responsible gene was not identified (van Vliet etal., 1995). Here we present the characterization of cmrl, a $\mathrm{Cu}^{2+}$ sensitive mutant, and the cloning of the corresponding gene. CMR1 is not only involved in $\mathrm{Cu}$ tolerance but also more generally in growth under normal, and especially under abiotic, stress conditions. 


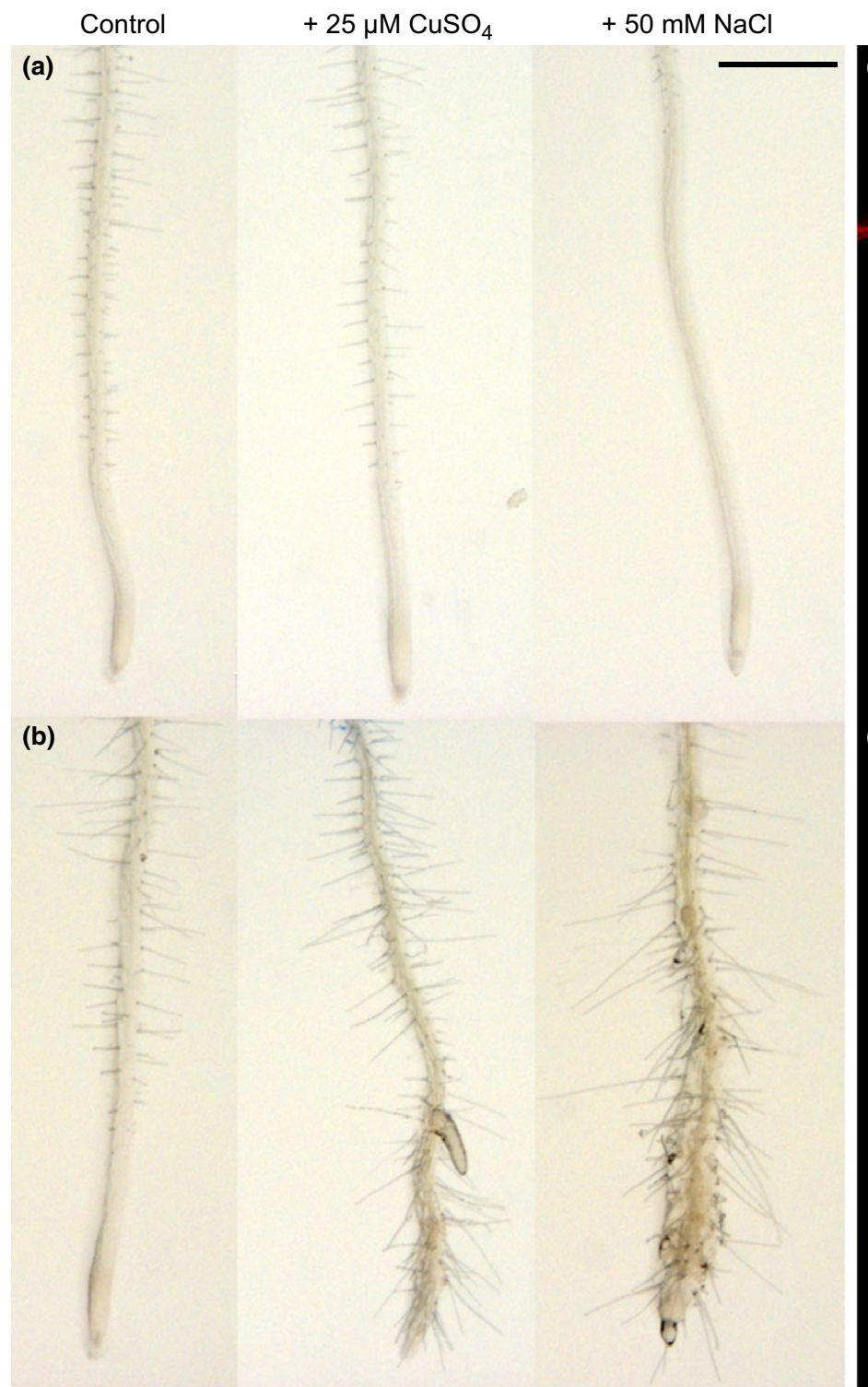

(e)

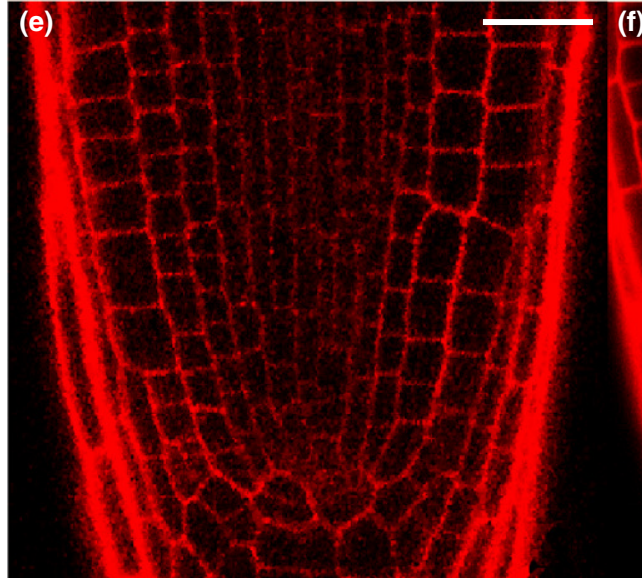

(f)

WT MS/2

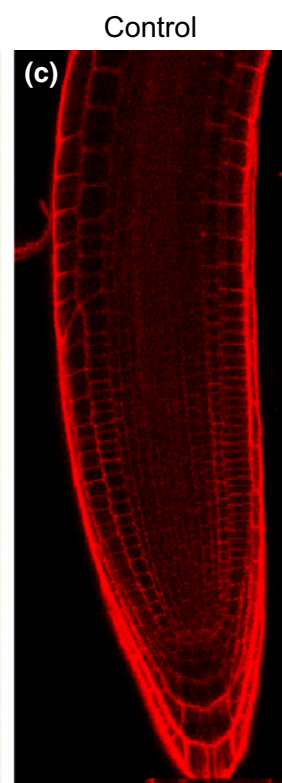

$+25 \mu \mathrm{M} \mathrm{CuSO}{ }_{4}$

$+50 \mathrm{mM} \mathrm{NaCl}$

(d)
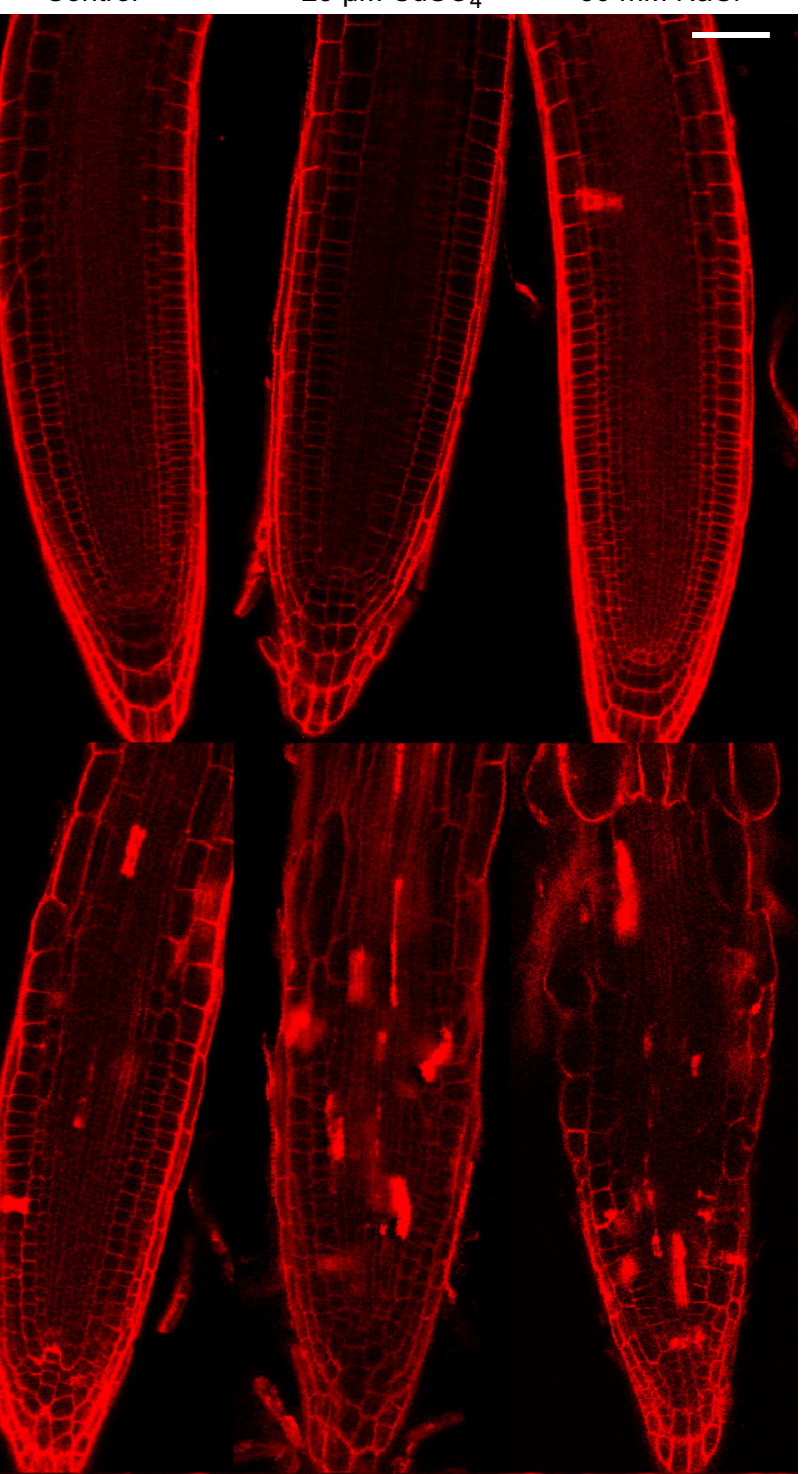

(g)

4

4

Fig. 6 Impact of $\mathrm{Cu}^{2+}$ and $\mathrm{Na}^{+}$excess on root tip morphology and root meristem in cmr1-1 and cmr1-2 Arabidopsis mutants. (a, b) Pictures of representative primary root (PR) tips of wild-type (WT) (a) and cmr1-1 (b), $6 \mathrm{~d}$ after transfer onto MS/2 (0.1 $\left.\left.\mu \mathrm{M}^{\text {CuSO }}\right)_{4}\right)$ medium supplemented with $25 \mu \mathrm{M} \mathrm{CuSO}_{4}$ or $50 \mathrm{mM} \mathrm{NaCl}$. Bar, $500 \mu \mathrm{m}$. (c-g) Pictures of representative propidium iodide-stained root tips and magnifications of their quiescent centres in 7-d-old WT (c,e) and in the cmr1-2 mutant ( $d, f, g)$ seedlings $24 \mathrm{~h}$ after transfer onto MS/2 medium, or the same medium supplemented with $25 \mu \mathrm{M} \mathrm{CuSO}_{4}$ or $50 \mathrm{mM} \mathrm{NaCl}$. Triangles indicate arbitrarily inserted cell walls. Bars: (c) $50 \mu \mathrm{m}$; (e) $20 \mu \mathrm{m}$. 


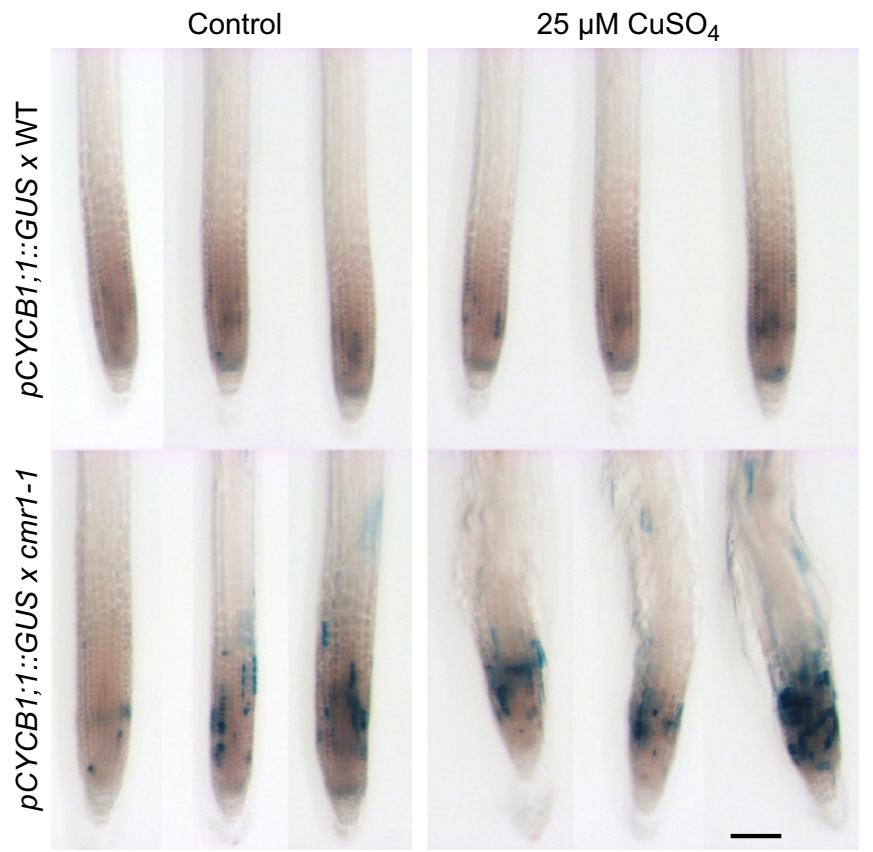

Fig. 7 Effect of $\mathrm{Cu}^{2+}$ excess on $C Y C B 1 ; 1$ expression in primary root (PR) tips of the Arabidopsis $c m r 1$ mutant. The $p C Y C B 1 ; 1:: G U S$ reporter line was used as a control to $P C Y C B 1 ; 1::$ GUS introgression into the $c m r 1-1$ background. Seedlings were transferred $5 \mathrm{~d}$ after germination onto plates containing MS/2 medium supplemented with or without $25 \mu \mathrm{M} \mathrm{CuSO}_{4}$ for $48 \mathrm{~h}$. Bar, $500 \mu \mathrm{m}$.

\section{Identification of the $\mathrm{cmr} 1$ mutation and cloning of the CMR1 gene}

The frequency of identified $\mathrm{Cu}^{2+}$-sensitive mutants appeared relatively low $\left(4.7 \times 10^{-5}\right)$ as compared with those reported in the literature (Howden \& Cobbett, 1992; Wu et al., 1996; Zhu et al., 1998). Several explanations can be found: mutants displaying weaker phenotype may have gone undetected; we can assume that the mechanisms of $\mathrm{Cu}$ tolerance are of such importance for plant survival that mutants affected in $\mathrm{Cu}$ detoxification mechanisms are lethal (Howden \& Cobbett, 1992); and functional redundancy between the components of $\mathrm{Cu}$ detoxification mechanisms could have hampered the identification of sensitive mutants, a hypothesis also suggested by Howden \& Cobbett (1992) to explain their low frequency observed in the screen for Cd-sensitive mutants. Nonetheless, our work describes the first successful identification of a mutant on high-Cu medium.

A map-based approach was undertaken to identify the position of the cmr 1-1 mutation and the gene was eventually cloned using transcriptomics and next-generation sequencing on a mutant pool. Based on the read mappings, a large rearrangement in cmr1-1 involving a $65 \mathrm{~kb}$ inversion between At3g14190 and At3g14310 loci was identified. To our knowledge, such a genomic rearrangement after FN mutagenesis is quite exceptional in a plant genome. Deletions and inversions ranging from several bp to $30 \mathrm{~kb}$ have been described previously (Shirley et al., 1992; Li \& Zhang, 2002; Belfield et al., 2012). However, another example, a large $460 \mathrm{~kb}$ deletion, was detected in a soybean supernodulation FN37 mutant (Men et al., 2002). As a consequence of the inversion, the At3g14190 CDS was placed under the activity of the At3g14310 promoter in cmr1-1. According to Genevestigator, the At3g14310 promoter activity is higher than the one of At3g14190, explaining why expression of the At3g14190 gene was higher in cmr1-1. Furthermore, the translation initiation codon of the At3g14310 gene was not in frame, implying that the At3g14310-encoded pectin methylesterase 3 was not functional in cmr1-1. However, the disruption of the At3g14310 gene had no impact on the cmrl-1 $\mathrm{Cu}^{2+}$-sensitive phenotype. This observation is consistent with the recent results of Weber et al. (2013) on pme3 loss-of-function mutants. An allelism test using cmr1-1 and $c m r 1-2$, as well as complementation of the SALK_070337 line with the At3g14190 genomic fragment both validated the identity of At3g14190 as the CMR1 gene. Ogawa et al. (2011) have described an RSS1 protein that maintains meristematic activity in both shoots and roots under stress conditions in rice. RSS1 is homologous to the protein encoded by the At3g14190 gene. Like CMR1, RSS1 possesses a D-box in its $\mathrm{N}$ terminus and is localized both in the nucleus and in the cytosol.

\section{Role of CMR1 in the regulation of growth in control and stress conditions}

The fact that the root growth was slightly but significantly affected in control conditions supports a role for CMR1 in normal plant growth and development. Detailed observation of the root meristem showed an impairment in the establishment of the cell division plane, but only with a weak impact on root length and growth. There was no significant growth reduction of the cmrl shoot in control conditions, suggesting that shoot apical meristem was not affected by the loss of function of CMR1. The analysis of shoot phenotype requires further studies. By contrast, the phenotype was more pronounced, but to a similar level, in both $c m r 1$ mutant alleles under $\mathrm{Cu}$ excess, indicating that the presence of CMR1 is crucial for development during stress conditions. Similarly to cup 1-1, stress sensitivity of $\mathrm{cmrl}$ was not restricted to $\mathrm{Cu}$. A strong growth reduction of PRs and LRs was observed upon all tested abiotic stresses $\left(\mathrm{CdSO}_{4}, \mathrm{CoCl}_{2}, \mathrm{KCl}\right.$, $\mathrm{K}_{2} \mathrm{SO}_{4}, \mathrm{LiCl}, \mathrm{MnCl}_{2}, \mathrm{NaCl}, \mathrm{Na}_{2} \mathrm{SO}_{4}, \mathrm{ZnCl}_{2}$ and sorbitol). Furthermore, upon exposure to $\mathrm{CdSO}_{4}, \mathrm{CuSO}_{4}, \mathrm{NaCl}$ and $\mathrm{ZnCl}_{2}$, the root phenotype of $\mathrm{cmrl}$ mutants also included a swelling of the RT, an outgrowth of RHs close to the root apex and a lengthening of RHs. Several observations, such as the higher ethylene production, might account for the root phenotype. It was demonstrated that the ethylene-induced root growth inhibition was associated with a reduction in meristem size caused by a premature differentiation of cells (Thomann et al., 2009). Here we showed that upon $\mathrm{Cu}^{2+}$ excess, $\mathrm{cmrl}$ overproduced ethylene in vitro. However, the inhibitors of ethylene biosynthesis were not able to restore the $\mathrm{cmrl}$ phenotype significantly, suggesting that ethylene did not directly induce growth inhibition. GUS staining of pACS4::GUS lines indicated an induction of ACS4 expression in the $\mathrm{cmrl}$ root apex $48 \mathrm{~h}$ after transfer onto $\mathrm{Cu}$-enriched medium (Arteca \& Arteca, 2007). This result showed a localized induction of ethylene production in the $\mathrm{cmrl}$ root apex, which could be related to the RT swelling and the 

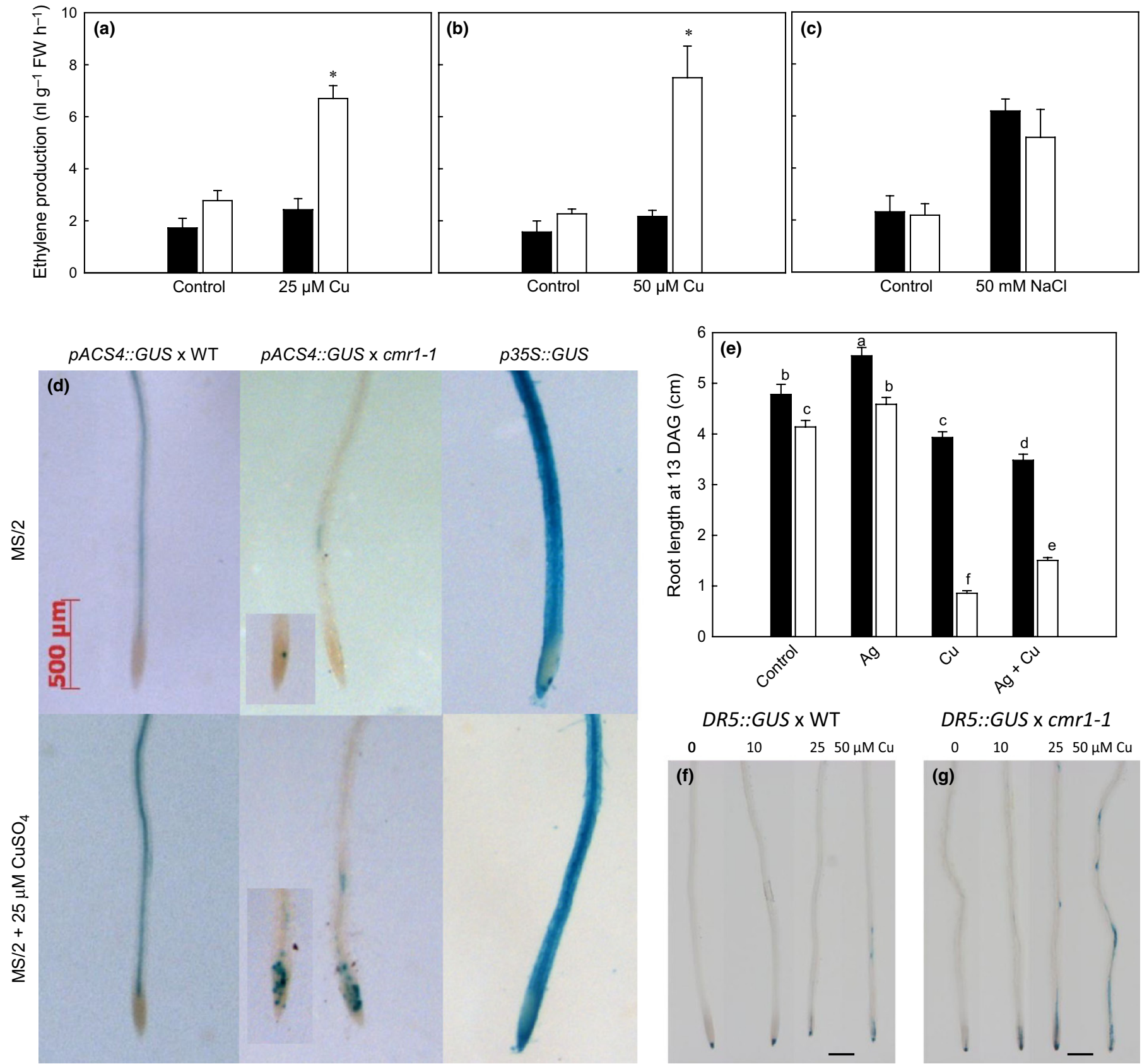

\section{DR5::GUS $\times$ WT}

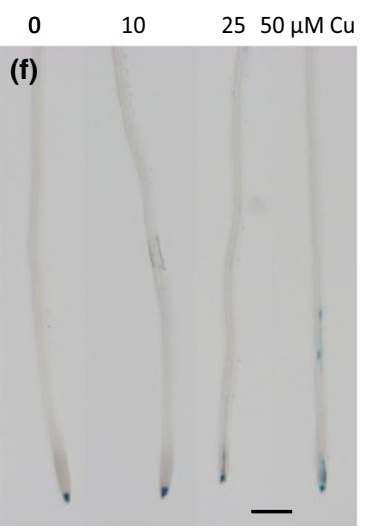

DR5::GUS $\times$ Cmr1-1

$0 \quad 10 \quad 2550 \mu \mathrm{MCu}$

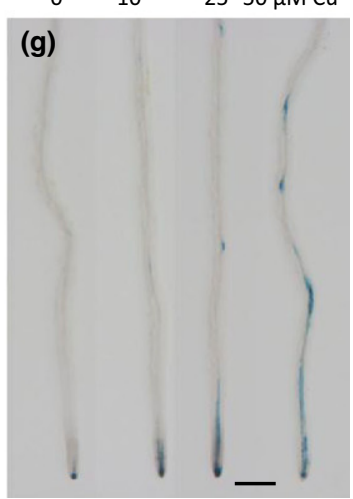

Fig. 8 Impact of $\mathrm{Cu}^{2+}$ and $\mathrm{Na}^{+}$excess on hormonal imbalance in in vitro-grown Arabidopsis $\mathrm{Cmr1-1}$ plantlets. (a-c) Effect of $\mathrm{Cu}^{2+}$ or salt excess on ethylene production by 9 - $d$-old $c m r 1-1$ seedlings grown on $M S / 2$ medium (control), or the same medium supplemented with $25 \mu M \mathrm{CuSO}_{4}$ (a), $50 \mu \mathrm{M}$ $\mathrm{CuSO}_{4}$ (b) or $50 \mathrm{mM} \mathrm{NaCl}$ (c). Wild-type (WT), black bars; cmr1-1, white bars. Average values ( $n=30$ seedlings from three independent growth experiments) \pm SE. For each growth condition, measurements were concurrently monitored and repeated at least three times. Asterisks denote significant differences between genotypes at $P \leq 0.05$. (d) Impact of $\mathrm{Cu}^{2+}$ excess on ACS4 expression in primary root (PR) tips in $\mathrm{cmr1-1}$. Seedlings were transferred $5 \mathrm{~d}$ after germination onto MS/2 or the same medium supplemented with $25 \mu \mathrm{M} \mathrm{CuSO}$ for $48 \mathrm{~h}$. Bar, $500 \mu \mathrm{m}$. (e) Impact of silver ions on the $\mathrm{cmr} 1-1$ $\mathrm{Cu}^{2+}$-sensitive root phenotype. PR length was measured $13 \mathrm{~d}$ after germination (DAG); 5 -d-old seedlings were transferred onto MS/2 or the same medium supplemented with $25 \mu \mathrm{M} \mathrm{CuSO}_{4}$ and/or $1 \mu \mathrm{M} \mathrm{Ag}_{2} \mathrm{SO}_{4}$. WT, black bars; cmr1-1, white bars. Average values ( $n \geq 30$ from three different growth experiments) $\pm \mathrm{SE}$. Letters denote significant differences between treatments at $P \leq 0.05$. (f, g) Effect of $\mathrm{Cu}^{2+}$ excess on auxin distribution in PR tips in the cmr1-1 mutant. $\beta$-Glucuronidase (GUS) staining of the root apex of the DR5::GUS reporter (f) and DR5::GUS $\times$ cmr1-1 lines (g). Seedlings were transferred $5 \mathrm{~d}$ after germination onto plates containing MS/2 medium or media supplemented with different $\mathrm{CuSO}_{4}$ concentrations for $24 \mathrm{~h}$. Bars, $500 \mu \mathrm{m}$.

formation of RHs close to the root apex. In addition, ethylene may also be responsible for the $\mathrm{RH}$ elongation. Indeed, eto mutants which overproduce ethylene were shown to produce longer RHs than the WT (Pitts et al., 1998). Synergistic effects of auxin and ethylene on root growth have been extensively studied using Arabidopsis mutants defective in ethylene and auxin signalling (Rủžička et al., 2007; Stepanova et al., 2007; Swarup et al., 2007). Ethylene was previously shown to promote auxin 
biosynthesis in roots by the activation of several auxin biosynthesis genes (Stepanova \& Alonso, 2005). Accordingly, an increase in DR5::GUS staining in RTs of $\mathrm{Cu}^{2+}$-treated $c m r 1$ may reflect the ethylene-induced IAA accumulation. In addition, mutants with altered responses to auxin also show defects in $\mathrm{RH}$ length, suggesting that, apart from ethylene, auxin also plays a role in controlling RH growth (Pitts et al., 1998; Rahman et al., 2002).

Since maintenance of cellular potassium concentrations is critical for salt tolerance (Zhu et al., 1998), the $\mathrm{Na}^{+}$-sensitive phenotype of the $c m r 1$ mutant could be associated with impaired $\mathrm{K}^{+}$ homeostasis. Roots deprived of $\mathrm{K}^{+}$were shown to induce the expression of genes involved in ethylene biosynthesis and signalling (Shin \& Schachtman, 2004). More recently, Jung et al. (2009) demonstrated a role of ethylene signalling in low $\mathrm{K}^{+}$-induced plant responses in Arabidopsis. It was shown that the low $\mathrm{K}^{+}$-induced ethylene synthesis in turn stimulated the production of ROS in the RH-forming zone, resulting in $\mathrm{RH}$ elongation and induction of the high-affinity $\mathrm{K}^{+}$uptake transporter HAK5, which contributes to the plant survival (Jung et al., 2009). Ethylene overproduction in $\mathrm{cmrl}$ upon $\mathrm{Cu}$ stress is probably not directly induced by altered $\mathrm{K}$ concentration, as $\mathrm{K}$ concentration was also lower in control conditions without concomitantly increased ethylene concentration. Besides, the addition of $\mathrm{K}^{+}$ upon $\mathrm{Cu}$ excess did not restore WT pACS4::GUS expression in the RT (data not shown), strongly suggesting that elevated ethylene production in $\mathrm{cmrl-1}$ was not a direct consequence of lower $\mathrm{K}^{+}$content. The fact that the addition of ethylene inhibitors or $\mathrm{Ca}\left(\mathrm{NO}_{3}\right)_{2}$ only partially restored the root growth in cmrl in stress conditions suggests that another affected process impairs root growth.

There are several features of the $\mathrm{cmrl}$ phenotype pointing to a deregulation in the cell cycle: inhibition of root growth, cell division defects and the outgrowth of RHs close to RT, which is a sign of a root meristem shrinkage (Culligan et al., 2004; De Schutter et al., 2007). We have observed similarities between the phenotype of $c m r 1$ and weel. WEE1 is a cell cycle regulatory kinase that is activated upon cessation of DNA replication or DNA damage (De Schutter et al., 2007). WEE1 knockout plants displayed root growth arrest in the presence of DNA-damaging chemicals, similar to that of $\mathrm{Cu}$ - or salt-grown $\mathrm{cmrl}$ (De Schutter et al., 2007; Cools etal., 2011). The phenotype in weel was attributable to a failure to block its cell cycle in response to DNA stress. The cells progressed into mitosis prematurely, resulting in a loss of genome integrity. The overexpression of WEE1 resulted in a strong reduction of the meristematic zone, cell cycle arrest, outgrowth of RHs close to RT and premature cell differentiation. It is thus not excluded that, analogously to WEE1, CMR1 is involved in mitosis regulation. An increased number of cells expressing the $p$ CYCB 1;1::GUS construct, especially upon $\mathrm{Cu}^{2+}$ excess, was observed in the PR meristem of $\mathrm{cmrl}$. Considering growth inhibition, this result may reflect a G2/M delay or arrest, resulting in a higher number of cells expressing the mitotic marker CYCB1;1 (Zhu etal., 2006; De Schutter etal., 2007; Dohmann et al., 2008). Similar results were observed in csn affected in the COP9 signalosome, which plays a role in the G2 phase progression (Dohmann etal., 2008) or in plants overexpressing the WEE1 kinase (De Schutter et al., 2007). However, Wu et al. (2010) have recently suggested that an accumulation of CYCB1;1 could also be associated with a defect in microtubule organization rather than an arrest in the cell cycle. They noticed that many mutants which accumulated CYCB 1;1 were affected in organ polarity and presented a root swelling. PI staining revealed severe alterations in cell division plane establishment in root meristems, which could indeed suggest a microtubule defect during formation of the mitotic spindle. Moreover, Wu etal. (2010) showed an accumulation of CYCB1;1 in a mutant affected in microtubule organization without any arrest in the cell cycle.

Interestingly, the At3g14190 gene was differentially expressed across several microarrays related to the cell cycle (Beemster et al., 2005; Menges etal., 2005; Dewitte etal., 2007; Cools et al., 2011; Heyndrickx \& Vandepoele, 2012). The analysis of cisacting regulatory elements, by means of PLACE (www.dna.affrc. go.jp/PLACE/), in the upstream region of CMR1 revealed several motifs found in the promoter of genes involved in the cell cycle or expressed in meristematic regions (Table S8; Planchais et al., 2002; Ramirez-Parra etal., 2003; Trémousaygue et al., 2003). According to Genevestigator, CMR1 was shown to be highly expressed in shoot and root meristems, which are the main sites of dividing cells. Moreover, the presence of a D-box supports the involvement of the protein in cell cycle-dependent protein turnover. We also observed that the cell cycle category was overrepresented in genes differentially regulated in $\mathrm{cmrl}$ relative to WT (Table S9). Finally, the transient expression of CMR1 fused to GFP in tobacco protoplasts confirmed the predicted nuclear localisation.

The resemblance between the $c m r 1$ phenotype and that of rss 1 is also significant. The latter was shown to be $\mathrm{NaCl}-, \mathrm{LiCl}-$ and sorbitol-sensitive. Root growth and meristem size were strongly reduced under salinity conditions, so that the differentiation zone appeared close to RT. However, in contrast to $c m r 1$, rss 1 has no particular phenotype in normal growth conditions. RSS1 is predominantly expressed in root and shoot meristems, most abundantly during the G1 and S phases. RSS1 was proposed to antagonize the G1/S checkpoint in response to stress and induce a slower cell cycle progression to equilibrate cell division with cell differentiation. It is therefore not excluded that CMR1 plays a similar role to RSS1 in maintaining meristematic activity under saline conditions, but CMR1 also plays a role, though to a lesser extent, in root growth under control conditions.

In contrast to rss 1 , a defect in $\mathrm{K}$ homeostasis in $c m r 1$ was shown. By using $\mathrm{K}^{+}$channel blockers on synchronized BY-2 cells, Sano et al. (2007) demonstrated that a cellular $\mathrm{K}^{+}$threshold was required for cells to re-enter the cell cycle from the G1 to the $S$ phase. This $\mathrm{K}^{+}$threshold is thought to be necessary for the proper turgor regulation of cycling cells. Interestingly, they showed that the expression of some $\mathrm{K}^{+}$transporters was modulated during the cell cycle progression. For example, the inward-rectifying channel gene $N K T 1$ was shown to be predominantly expressed in the G1 phase and responsible for $\mathrm{K}^{+}$uptake during the G1-to-S phase transition. An Arabidopsis NKT1 ortholog, AKT1, is involved in $\mathrm{K}^{+}$uptake by roots (Hirsch et al., 1998). It is therefore possible 
that the putative cell cycle defect in $c m r l$ has an impact on the $\mathrm{K}^{+}$ uptake detected in normal and stress conditions. In agreement with this, our microarrays revealed several differences in the expression of $\mathrm{K}^{+}$transporters between the WT and $c m r 1-1$. For instance, KCO1 and AKT5, outward- and inward-rectifying K channels, respectively, were more strongly expressed in $\mathrm{Cu}^{2+}$ treated roots of $c m r 1-1$ than in the WT (Table S10), which was confirmed by RT-PCR (data not shown). In addition, the $\mathrm{Na}^{+}$ transporter AtHKT1, which controls $\mathrm{Na}^{+}$homeostasis and in turn affects $\mathrm{K}^{+}$acquisition (Rus et al., 2004), was repressed in $\mathrm{Cu}^{2+}$-treated roots of $c m r 1-1$.

In summary, the present work describes a novel genetic factor involved in plant growth and stress response. Impairment of cmrl activity alters root growth, meristem activity, $\mathrm{K}$ content, and ethylene and IAA accumulation. Research into the role of CMR1 in maintaining meristematic activity is ongoing and will contribute to understanding the plasticity of plants in response to changing environments.

\section{Acknowledgements}

This work was supported by a grant from the Belgian National Fund for Scientific Research FNRS-FRFC 2.4.527.10.F 'Mechanisms of resistance to copper in bacteria and plants; evaluation of plant-bacteria interactions in plant resistance'. The authors thank V. Lionetti (Sapienza University of Rome, Italy) for pme3 seeds; R. Mercier (INRA Versailles-Grignon, France) for SALK_070337 transformed with At3g14190; N. von Wiren and S. Reiner (IPK Gatersleben, Germany) for ICP-OES analysis; F.J. Harren and S. Cristescu (Radboud University, Nijmegen, the Netherlands) for assistance with ethylene measurements carried out within the framework of the EU-FP6-Infrastructures-5 programme (project FP6-026183 Life Science Trace Gas Facility); O. Grandjean (INRA Versailles-Grignon, France) for confocal microscopy assistance; and P. Saumitou-Laprade (University of Lille, France) for access to the Light-Cycler 480. C.H. is an F.R.S-FNRS research associate.

\section{References}

Aloni R, Aloni E, Langhans M, Ullrich CI. 2006. Role of cytokinin and auxin in shaping root architecture: regulating vascular differentiation, lateral root initiation, root apical dominance and root gravitropism. Annals of Botany 97: 883-893.

Alonso JM, Ecker JR. 2006. Moving forward in reverse: genetic technologies to enable genome-wide phenomic screens in Arabidopsis. Nature Reviews Genetics 7: 524-536.

Andrés-Colás N, Perea-García A, Mayo de Andrés S, Garcia-Molina A, Dorcey E, Rodríguez-Navarro S, Pérez-Amador MA, Puig S, Peñarrubia L. 2013. Comparison of global responses to mild deficiency and excess copper levels in Arabidopsis seedlings. Metallomics 5: 1234-1246.

Andrés-Colás N, Sancenón V, Rodríguez-Navarro S, Mayo S, Thiele DJ, Ecker JR, Puig S, Peñarrubia L. 2006. The Arabidopsis heavy metal P-type ATPase HMA5 interacts with metallochaperones and functions in copper detoxification of roots. Plant Journal 45: 225-236.

Arteca RN, Arteca JM. 2007. Heavy-metal-induced ethylene production in Arabidopsis thaliana. Journal of Plant Physiology 164: 1480-1488.

Beemster GTS, De Veylder L, Vercruysse S, West G, Rombaut D, Van Hummelen P, Galichet A, Gruissem W, Inzé D, Vuylsteke M. 2005.
Genome-wide analysis of gene expression profiles associated with cell cycle transitions in growing organs of Arabidopsis. Plant Physiology 138: 734-743.

Belfield EJ, Gan X, Mithani A, Brown C, Jiang C, Franklin K, Alvey E, Wibowo A, Jung M, Bailey $\mathrm{K}$ et al. 2012. Genome-wide analysis of mutations in mutant lineages selected following fast-neutron irradiation mutagenesis of Arabidopsis thaliana. Genome Research 22: 1306-1315.

Burkhead JL, Gogolin Reynolds KA, Abdel-Ghany SE, Cohu CM, Pilon M. 2009. Copper homeostasis. New Phytologist 182: 799-816.

Cohu CM, Pilon M. 2007. Regulation of superoxide dismutase expression by copper availability. Physiologia Plantarum 129: 747-755.

Cohu CM, Pilon M. 2010. Cell biology of copper. Plant Cell Monographs 17: 55-74.

Colón-Carmona A, You R, Haimovitch-Gal T, Doerner P. 1999. Spatio-temporal analysis of mitotic activity with a labile cyclin-GUS fusion protein. Plant Journal 20: 503-508.

Cools T, Iantcheva A, Weimer AK, Boens S, Takahashi N, Maes S, Van den Daele H, Van Isterdael G, Schnittger A, De Veylder L. 2011. The Arabidopsis thaliana checkpoint kinase WEE1 protects against premature vascular differentiation during replication stress. The Plant Cell 23: 1435-1448.

Cristescu S, Mandon J, Arslanov D, De Pessemier J, Hermans C, Harren FJM. 2013. Current methods for detecting ethylene in plants. Annals of Botany 111: 347-360.

Culligan K, Tissier A, Britt A. 2004. ATR regulates a G2-phase cell-cycle checkpoint in Arabidopsis thaliana. The Plant Cell 16: 1091-1104.

De Schutter K, Joubès J, Cools T, Verkest A, Corellou F, Babiychuk E, Van Der Schueren E, Beeckman T, Kushnir S, Inzé D et al. 2007. Arabidopsis WEE1 kinase controls cell cycle arrest in response to activation of the DNA integrity checkpoint. The Plant Cell 19: 211-225.

Dewitte W, Scofield S, Alcasabas AA, Maughan SC, Menges M, Braun N, Collins C, Nieuwland J, Prinsen E, Sundaresan V et al. 2007. Arabidopsis CYCD3 D-type cyclins link cell proliferation and endocycles and are rate-limiting for cytokinin responses. Proceedings of the National Academy of Sciences, USA 104: 14537-14542.

Dohmann EMN, Levesque MP, De Veylder L, Reichardt I, Jürgens G, Schmid M, Schwechheimer C. 2008. The Arabidopsis COP9 signalosome is essential for G2 phase progression and genomic stability. Development 135: 2013-2022.

Drążkiewicz M, Skórzyńska-Polit E, Krupa Z. 2004. Copper-induced oxidative stress and antioxidant defence in Arabidopsis thaliana. BioMetals 17: 379-387.

Epstein E, Bloom AJ. 2005. Mineral nutrition of plants: principles and perspectives, $2^{\text {nd }} e d n$. Sunderland, MA, USA: Sinauer.

Gauthier NP, Larsen ME, Wernersson R, de Lichtenberg U, Jensen LJ, Brunak S, Jensen TS. 2008. Cyclebase.org - a comprehensive multi-organism online database of cell-cycle experiments. Nucleic Acids Research 36: D854-D859.

Gruber BD, Giehl RFH, Friedel S, von Wirén N. 2013. Plasticity of the Arabidopsis root system under nutrient deficiencies. Plant Physiology 163 : 161-179.

Hanikenne M, Krämer U, Demoulin V, Baurain D. 2005. A comparative inventory of metal transporters in the green alga Chlamydomonas reinhardtii and the red alga Cyanidioschyzon merolae. Plant Physiology 137: 428-446.

Hermans C, Porco S, Verbruggen N, Bush DR. 2010. Chitinase-like protein CTL1 plays a role in altering root system architecture in response to multiple environmental conditions. Plant Physiology 152: 904-915.

Heyndrickx KS, Vandepoele K. 2012. Systematic identification of functional plant modules through the integration of complementary data sources. Plant Physiology 159: 884-901.

Hichri I, Heppel SC, Pillet J, Léon C, Czemmel S, Delrot S, Lauvergeat V, Bogs J. 2010. The basic helix-loop-helix transcription factor MYC1 is involved in the regulation of the flavonoid biosynthesis pathway in grapevine. Molecular Plant 3: 509-523.

Hirsch RE, Lewis BD, Spalding EP, Sussman MR. 1998. A role for the AKT1 potassium channel in plant nutrition. Science 280: 918-921.

Howden R, Cobbett CS. 1992. Cadmium-sensitive mutants of Arabidopsis thaliana. Plant Physiology 99: 100-107.

Jung J-Y, Shin R, Schachtman DP. 2009. Ethylene mediates response and tolerance to potassium deprivation in Arabidopsis. The Plant Cell 21: 607-621.

Karimi M, Inzé D, Depicker A. 2002. Gateway vectors for Agrobacterium-mediated plant transformation. Trends in Plant Science 7: 193-195. 
Le J, Vandenbussche F, Van Der Straeten D, Verbelen J-P. 2001. In the early response of Arabidopsis roots to ethylene response pathway is up and down regulated and uncoupled from differentiation. Plant Physiology 125: 519-522.

Lequeux H, Hermans C, Lutts S, Verbruggen N. 2010. Response to copper excess in Arabidopsis thaliana: impact on the root system architecture, hormone distribution, lignin accumulation and mineral profile. Plant Physiology and Biochemistry 48: 673-682.

Li H, Durbin R. 2009. Fast and accurate short read alignment with Burrows-Wheeler Transform. Bioinformatics 25: 1754-1760.

Li X, Zhang Y. 2002. Reverse genetics by fast neutron mutagenesis in higher plants. Functional \& Integrative Genomics 2: 254-258.

Marschner H. 1995. Mineral nutrition of higher plants. London, UK: Academic Press.

Men AE, Laniya TS, Searle IR, Iturbe-Ormaetxe I, Gresshoff I, Jiang Q, Carroll BJ, Gresshoff PM. 2002. Fast neutron mutagenesis of soybean (Glycine soja L.) produces a supernodulating mutant containing a large deletion in linkage group H. Genome letters 3: 147-155.

Menges M, de Jager SM, Gruissem W, Murray JAH. 2005. Global analysis of the core cell cycle regulators of Arabidopsis identifies novel genes, reveals multiple and highly specific profiles of expression and provides a coherent model for plant cell cycle control. Plant Journal 41: 546-566.

Moubayidin L, Di Mambro R, Sabatini S. 2009. Cytokinin-auxin crosstalk. Trends in Plant Science 14: 557-562.

Murashige T, Skoog F. 1962. A revised medium for rapid growth and bio assays with tobacco tissue cultures. Physiologia Plantarum 15: 473-497.

Nibau C, Gibbs DJ, Coates JC. 2008. Branching out in new directions: the control of root architecture by lateral root formation. New Phytologist 179: 595-614.

Ogawa D, Abe K, Miyao A, Kojima M, Sakakibara H, Mizutani M, Morita H, Toda Y, Hobo T, Sato Y et al. 2011. RSS1 regulates the cell cycle and maintains meristematic activity under stress conditions in rice. Nature Communications 2: 278

Perilli S, Sabatini S. 2010. Analysis of root meristem size development. Methods in Molecular Biology 655: 177-187.

Pitts RJ, Cernac A, Estelle M. 1998. Auxin and ethylene promote root hair elongation in Arabidopsis. Plant Journal 16: 553-560.

Planchais S, Perennes C, Glab N, Mironov V, Inzé D, Bergounioux C. 2002. Characterization of $c i s$-acting element involved in cell cycle phase-independent activation of Arath; $C y c B 1 ; 1$ transcription and identification of putative regulatory proteins. Plant Molecular Biology 50: 111-127.

Potters G, Pasternak TP, Guisez Y, Jansen MAK. 2009. Different stresses, similar morphogenic responses: integrated a plethora of pathways. Plant, Cell \& Environment 32: 158-169.

Potters G, Pasternak TP, Guisez Y, Palme KJ, Jansen MAK. 2007.

Stress-induced morphogenic responses: growing out of trouble? Trends in Plant Science 12: 98-105.

Puig S, Thiele D. 2002. Molecular mechanisms of copper uptake and distribution. Current Opinion in Chemical Biology 6: 171-180.

Rahman A, Hosokawa S, Oono Y, Amakawa T, Goto N, Tsurumi S. 2002. Auxin and ethylene response interactions during Arabidopsis root hair development dissected by auxin influx modulators. Plant Physiology 130: 1908-1917.

Ramirez-Parra E, Fründt C, Gutierrez C. 2003. A genome-wide identification of E2F-regulated genes in Arabidopsis. Plant Journal 33: 801-811.

Rus A, Lee B-H, Muñoz-Mayor A, Sharkhuu A, Miura K, Zhu J-K, Bressan RA, Hasegawa PM. 2004. AtHKT1 facilitates $\mathrm{Na}^{+}$homeostasis and $\mathrm{K}^{+}$nutrition in planta. Plant Physiology 136: 2500-2511.

Rǔžička K, Ljung K, Vanneste $S$, Podhorská P, Beeckman T, Friml J, Benková E. 2007. Ethylene regulates root growth through effects on auxin biosynthesis and transport-dependent auxin distribution. The Plant Cell 19: 2197-2212.

Sancenón V, Puig S, Mateu-Andrés I, Dorcey E, Thiele DJ, Peñarrubia L. 2004. The Arabidopsis copper transporter COPT1 functions in root elongation and pollen development. The Journal of Biological Chemistry 279: 15348-15355.

Sano T, Becker D, Ivashikina N, Wegner LH, Zimmermann U, Roelfsema MRG, Nagata T, Hedrich R. 2007. Plant cells must pass a $\mathrm{K}^{+}$threshold to re-enter the cell cycle. Plant Journal 50: 401-413.

Schneeberger K, Ossowski S, Lanz C, Juul T, Petersen AH, Nielsen KL, Jørgensen J-E, Weigel D, Andersen SU. 2009. SHOREmap: simultaneous mapping and mutation identification by deep sequencing. Nature Methods 6: $550-551$.

Shabala S, Demidchik V, Shabala L, Cuin TA, Smith SJ, Miller AJ, Davies JM, Newman IA. 2006. Extracellular $\mathrm{Ca}^{2+}$ ameliorates $\mathrm{NaCl}$-induced $\mathrm{K}^{+}$loss from Arabidopsis root and leaf cells by controlling plasma membrane $\mathrm{K}^{+}$-permeable channels. Plant Physiology 141: 1653-1665.

Shin R, Schachtman DP. 2004. Hydrogen peroxide mediates plant root cell response to nutrient deprivation. Proceedings of the National Academy of Sciences, USA 101: 8827-8832.

Shin LJ, Lo JC, Yeh KC. 2012. Copper chaperone antioxidant protein1 is essential for copper homeostasis. Plant Physiology 159: 1099-1110.

Shirley BW, Hanley S, Goodman HM. 1992. Effects of ionizing radiation on a plant genome: analysis of two Arabidopsis transparent testa mutations. The Plant Cell 4: 333-347.

Smalle J, Van Der Straeten D. 1997. Ethylene and vegetative development. Physiologia Plantarum 100: 593-605.

Stepanova AN, Alonso JM. 2005. Ethylene signalling and response pathway: a unique signalling cascade with a multitude of inputs and outputs. Physiologia Plantarum 123: 195-206.

Stepanova AN, Yun J, Likhacheva AV, Alonso JM. 2007. Multilevel interactions between ethylene and auxin in Arabidopsis roots. The Plant Cell 19: 2169-2185.

Swarup R, Perry P, Hagenbeek D, Van Der Straeten D, Beemster GTS, Sandberg G, Bhalerao R, Ljung K, Bennett MJ. 2007. Ethylene upregulates auxin biosynthesis in Arabidopsis seedlings to enhance inhibition of root cell elongation. The Plant Cell 19: 2186-2196.

Tanimoto M, Roberts K, Dolan L. 1995. Ethylene is a positive regulator of root hair development in Arabidopsis thaliana. Plant Journal 8: 943-948.

Thomann A, Lechner E, Hansen M, Dumbliauskas E, Parmentier Y, Kieber J, Scheres B, Genschik P. 2009. Arabidopsis CULLIN3 genes regulate primary root growth and patterning by ethylene-dependent and -independent mechanisms. PLoS Genetics 5: e1000328.

Trémousaygue D, Garnier L, Bardet C, Dabos P, Hervé C, Lescure B. 2003. Internal telomeric repeats and 'TCP domain' protein-binding sites co-operate to regulate gene expression in Arabidopsis thaliana cycling cells. Plant Journal 33: 957-966.

Ulmasov T, Murfett J, Hagen G, Guilfoyle TJ. 1997. Aux/IAA proteins repress expression of reporter genes containing natural and highly active synthetic auxin response elements. The Plant Cell 9: 1963-1971.

Vandepoele K, Raes J, De Veylder L, Rouzé P, Rombauts S, Inzé D. 2002. Genome-wide analysis of core cell cycle genes in Arabidopsis. The Plant Cell 14: 903-916.

Verbruggen N, Hermans C. 2013. Root responses to trace metallic elements. In: Eshel A, Beeckman T, eds. Plant roots: the hidden half, $4^{\text {th }} e d n$. Boca Raton, FL, USA: CRC Press, 34-1-34-30.

van Vliet C, Andersen CR, Cobbett CS. 1995. Copper-sensitive mutant of Arabidopsis thaliana. Plant Physiology 109: 871-878.

Weber M, Deinlein U, Fischer S, Rogowski M, Geimer S, Tenhaken R, Clemens S. 2013. A mutation in the Arabidopsis thaliana cell wall biosynthesis gene pectin methylesterase 3 as well as its aberrant expression cause hypersensitivity specifically to Zn. Plant Journal 76: 151-164.

Wu S, Scheible W-R, Schindelasch D, Van Den Daele H, De Veylder L, Baskin TI. 2010. A conditional mutation in Arabidopsis thaliana separase induces chromosome non-disjunction, aberrant morphogenesis and cyclin B1;1 stability. Development 137: 953-961.

Wu S-J, Ding L, Zhu J-K. 1996. SOS1, a genetic locus essential for salt tolerance and potassium acquisition. The Plant Cell 8: 617-627.

Zhao C-R, Ikka T, Sawaki Y, Kobayashi Y, Suzuki Y, Hibino T, Sato S, Sakurai N, Shibata D, Koyama H. 2009. Comparative transcriptomic characterization of aluminium, sodium chloride, cadmium and copper rhizotoxicities in Arabidopsis thaliana. BMC Plant Biology 9: 32.

Zhu Y, Dong A, Meyer D, Pichon O, Renou J-P, Cao K, Shen W-H. 2006. Arabidopsis NRP1 and NRP2 encode histone chaperones and are required for maintaining postembryonic root growth. The Plant Cell 18: 2879-2892.

Zhu J-K, Liu J, Xiong L. 1998. Genetic analysis of salt tolerance in Arabidopsis: evidence for a critical role of potassium nutrition. The Plant Cell 10: $1181-1191$. 


\section{Supporting Information}

Additional supporting information may be found in the online version of this article.

Fig. S1 Illustration of the fine-mapping evolution of the $\mathrm{cmrl}$ Arabidopsis mutant.

Fig. S2 Root length of 15-d-old pme3 (At3g14310) seedlings exposed to high-Cu or salt conditions.

Fig. S3 Detection of a mutation at the At3g14190 locus.

Fig. S4 Coverage of cmr1-1 reads onto the Col-0 WT Arabidopsis reference genome.

Fig. S5 Magnification of two low-coverage regions and analysis of $c m r l$ pair reads.

Fig. S6 Nature of the $c m r 1$ mutation and genomic sequence of the hybrid At3g14190 gene.

Fig. S7 Impact of $\mathrm{Cu}^{2+}$ and $\mathrm{Na}^{+}$excess on $c m r 1-1$ and WT Arabidopsis biomass in hydroponics.

Fig. S8 Allelism test between Arabidopsis cmr1-1 and T-DNA mutants at the At3g14190 locus.

Table S1 Number of $\mathrm{M}_{2}$ Arabidopsis seedlings screened in vertical plates

Table S2 List of the 53 candidate genes located in the $184 \mathrm{~kb}$ region of interest delimited by the fine-mapping of the $\mathrm{cmrl}$ Arabidopsis mutant
Table S3 Microarray analysis of the genes lying in the $184 \mathrm{~kb}$ region delimited by the fine-mapping of $\mathrm{cmrl}$ and whose expression was differentially regulated in $c m r l$ as compared with WT

Table S4 List of T-DNA insertion mutants available at the At3g14190 locus

Table S5 Mineral profile of the in vitro-grown cmr1-2 mutant and WT Arabidopsis plants

Table S6 Potassium concentrations in the in vitro-grown Arabidopsis cmr1-1 mutant and T-DNA SALK_035661 lines

Table S7 Molecular markers used in the map-based cloning of the $c m r 1$ Arabidopsis mutant

Table S8 List of potential cis-acting regulatory elements identified in the $5^{\prime}$ regulatory sequence of the CMRI Arabidopsis gene

Table S9 List of genes related to the cell cycle differentially regulated in $c m r 1-1$ compared with WT

Table S10 List of genes related to potassium homeostasis differentially regulated in $c m r 1-1$ compared with WT (cutoff $=3$ )

Table S11 List of primers used in genotyping of both $\mathrm{cmrl}$ mutant alleles (positions of primers are relative to the translation initiation codon) and cloning of CMR1 CDS

Please note: Wiley Blackwell are not responsible for the content or functionality of any supporting information supplied by the authors. Any queries (other than missing material) should be directed to the New Phytologist Central Office. 